\title{
Progress and applications of mouse models for human lung cancer
}

\author{
S. de Seranno and R. Meuwissen
}

\begin{abstract}
The continued progress of modelling lung cancer in mice has led not only to new means of understanding the molecular pathways governing human lung cancer, but it has also created a vast reservoir of alternative tools to test treatments against this malignancy. More sophisticated somatic mouse models for nonsmall cell lung cancer, small cell lung cancer and pulmonary squamous cell carcinoma have been generated that closely mimic human lung cancer. These models enable us to identify the cells of origin and the role of stem cells in the maintenance of the various types of lung cancer. Moreover, results of lung cancer intervention studies are now starting to reveal the full potential of these somatic mouse models as powerful pre-clinical models.
\end{abstract}

\section{KEYWORDS: Lung cancer, mouse models, nonsmall cell lung cancer, small cell lung cancer}

(D) rogress in whole genome approaches to detect genetic alterations in human lung cancer has resulted in the identification of a growing number of lung cancer-related genes. Genome-wide association studies, whether they are based on single-nucleotide polymorphism array studies or detecting changes in gene copy numbers via comparative genomic hybridisation arrays, link the occurrence and frequency of mutations in lung cancer-related genes to the well-defined phenotype of high numbers of human lung cancer. These lung cancer-related genes provide great potential as therapeutic targets for lung cancer intervention. Target validation then occurs through in vitro intervention studies of these specific genetic mutations and their respective molecular pathways in human lung cancer cell lines. However, in vitro cell culture studies are limited and cannot fully mimic the more complex in vivo onset of tumorigenesis and response to tumour therapy. Developing lung cancer in mouse models that harbour specific mutations will undoubtedly provide a further and better insight into the mutation-specific effects on lung tumour biology. Moreover, a high degree of pathophysological similarity between lung tumours from mouse models and their human counterparts will make it possible to use these mouse models for pre-clinical tests. Various intervention strategies against specific mutations can then be tested based on better evaluation of both specificity and efficacy in mouse lung tumours of every developing stage. Continuous innovation of techniques to manipulate the mouse genome has enabled us to adjust compound mouse models of lung cancer in such a way that they start to reproduce the more complex human lung cancer in a higher degree. Complementary to this, the number of genetically engineered mouse models for lung cancer is ever expanding.

\section{FIRST MOUSE MODELS FOR LUNG CANCER}

The use of mouse models for spontaneous or chemically induced lung tumours has a long

Previous articles in this series: No. 1: De Wever W, Stroobants S, Coden J, et al. Integrated PET/CT in the staging of nonsmall cell lung cancer: technical aspects and resection for lung cancer. Eur Respir J 2009; 33: 201-212. No. 2: Rami-Porta R, Tsuboi M. Sublobar resection for lung cancer. Eur Respir J 2009; 33 : 426-435. No. 3: McWilliams A, Lam B, Sutedja T. Early proximal lung cancer diagnosis and treatment. Eur Respir J 2009; 33: 656-665. No. 4: Sculier J-?P, Moro-Sibilot D. First- and second-line therapy for advanced nonsmall cell lung cancer. Eur Respir J 2009; 33: 916-930. No. 5: van Tilburg PMB, Stam H, Hoogsteden HC, et al. Pre-operative pulmonary evaluation of lung cancer patients: a review of the literature. Eur Respir J 2009; 33: 1206-1215. No. 6: Brambilla E, Gazdar A. Pathogenesis of lung cancer signalling pathways: roadmap for therapies. Eur Respir J 2009; 33: 1482-1494. No. 7: Horváth I, Lázár Z, Gyulai N, et al. Exhaled biomarkers in lung cancer. Eur Respir J 2009; 34: 261-275. No. 8: 0cak S, Sos ML, Thomas RK, et al. High-throughput molecular analysis in lung cancer: insights into biology and potential clinical applications. Eur Respir J 2009; 34: 489-506. No. 9: Field JK, Liloglou T, Niaz A. et al. EUELC project: a multi-centre, multipurpose study to investigate early stage NSCLC, and to establish a biobank for ongoing collaboration. Eur Respir J 2009; 34: 1477-1486. No. 10: Demedts IK, Vermaelen KY, van Meerbeeck JP. Treatment of extensive-stage small cell lung carcinoma: current status and future prospects. Eur Respir J 2010; 35: 202-215.

AFFILIATIONS

Institut Albert Bonniot, Cancer Research Center INSERM U823; Université Joseph Fourier, Grenoble, France.

\section{CORRESPONDENCE}

R. Meuwissen

Institut Albert Bonniot

Centre de Recherche INSERM U823

Equipe 2

UJF-Domaine de la Merci

BP 170

38042 Grenoble

Cedex 9

France

E-mail: ralph.meuwissen@

ujf-grenoble.fr

Received:

Aug 042009

Accepted after revision:

Aug 102009 
history. While susceptibility and incidence of spontaneous lung tumours varies between well-established mouse-inbred strains, all their molecular pathologies share many similarities with human lung cancer [1]. This was clearly established in early studies in which defined chemical carcinogens were used to induce lung tumours [1]. Incidence of spontaneous and induced lung tumours were both at the highest $(61 \%)$ in sensitive strains such as A/J and SWR, but very low (6\%) in highly resistant strains C57BL6 and DBA for males at 2 yrs [1]. Contrary to human lung cancer with its complex molecular genetics and four distinct tumour types that readily metastasise, spontaneous and chemically induced lung lesions in mice often result in pulmonary adenomas [2] and more infrequent adenocarcinomas, which almost never metastasise. Mouse lung tumour development shows initial hyperplastic foci in bronchioles and alveoli, which then become benign adenomas and eventually adenocarcinomas [2]. The very reproducible tumour latency obviously depends on strain susceptibility and/or application of carcinogen-induction protocols. Most potent carcinogens are the cigarette smoke carcinogens, such as polycyclic aromatic hydrocarbons, tobacco-specific nitrosamine and benzo[a]pyrene $(\mathrm{B}[\mathrm{a}] \mathrm{P})[3]$. However, cigarette smoke itself is sufficient to induce reproducibly lung tumours in A/J mice after a 5-month exposure period followed by a crucial 4-month recovery period [4]. Exposure of B6C3F1 female mice to life-time (30 months) cigarette smoke resulted in $48 \%$ benign and malignant lung tumours through distinct (epi)genetic pathways [5]. Therefore, there are clear differences between (spontaneous) murine and human lung tumours. It has been especially hard to replicate the well-characterised pre-malignant lesions in human airway epithelium [6]. Nevertheless, major histopathological similarities remain and molecular characterisation of spontaneous and carcinogen-induced murine lung tumours revealed a high degree of genetic lesions compared to their human counterparts [7]. A prominent early event is the occurrence of activating Kras mutations [7] in hyperplastic lesions. Besides over expression of cMYC, inactivation of well-known tumour suppressor genes, such as Tumour suppressor protein 53 (Trp53), Fragile histidine triad protein (fhit), adenomatous polyposis coli protein (APC), retinoblastoma protein (RB), mutated in colorectal carcinoma protein (MCC) and $\mathrm{p} 16^{\mathrm{INK} 4 \mathrm{~A}}$ (CDKN2A) [7], readily occur; most frequently adenomas develop which only sporadically progress into adenocarcinomas. Differences in susceptibility to lung cancer development between various mice strain remain, however, very intriguing. Most susceptible strains, such as A/J and BALB/C, do have a polymorphism in intron 2 of $\mathrm{Kras}[8,9]$ and a CDKN2a polymorphism was found in BALB/C, influencing their sensitivity to lung cancer. Due to the genome wide sequence analysis, efforts in more interesting polymorphism information of various mice strains is likely to follow and can then be compared with human syngeneic counterparts found in large panels of human lung cancer genome data. Moreover, as we will see in later in this review, more direct transgenic models will be very suitable to cross into resistant strains in order to facilitate the direct search for modifying genes of lung tumour susceptibility.

\section{TRANSGENIC MICE}

\section{First generation}

The first generation of transgenic models was based on ectopic transgene expression under control of heterologous promoters.
Expression is mainly targeted to specific subsets of lung epithelial cells: surfactant protein-C promoter directs expression primarily to type II alveolar cells whereas Clara cell secreatory protein (CCSP)/CC10 promoters mainly target the nonciliated secretory (Clara) cells along the airways. SV40 Tag (Simian virus large T-antigen) was constitutively expressed behind CCSP [10, 11] or surfactant protein (SP)-C promoters [12]. Although each tumour originated from either type II alveolar or Clara cells, they both resulted in quite similar aggressive adenocarcinomas without metastases [13]. A similar strategy was used for different oncogenes (such as cRaf and $c M y c$ [14]), however, with a milder phenotype, as both transgenic mice mainly ended up in having adenomas and a few progressed adenocarcinomas, again without any metastases.

Many prominent genetic lesions found in human lung cancer clearly link the inactivation of well-known tumour suppressor genes [15] to lung cancer development. Initial attempts to mimic some of these lesions implicated in lung cancer by way of conventional knockout mice studies had rather limited success with respect to the onset of lung cancer. The main reason for this was that germ-line deletion of many essential tumour suppressor genes (such as the retinoblastoma gene $(R b)$ and wilms tumour-1 homolog gene (Wt-1) [16]) lead to embryonal or perinatal lethality. Nonessential tumour suppressor gene knockout mice with a longer life-span often had a very broad tumour spectrum of which lung tumours formed only a minor fraction. Thus, Trp53, $p 16^{I N K 4 A}$ and $p 19^{A R F}$ [17] homozygous null allele mice seldom develop lung adenocarcinomas. However, introducing similar mutations into endogenous Trp53 alleles, such as those prominently found in $\mathrm{Li}-$ Fraumeni patients, generated $\operatorname{Trp} 53^{R 270 H /+}$ and $\operatorname{Trp} 53^{R 172 H /+}$ which had a different tumour spectrum compared with $\mathrm{Trp}_{53}{ }^{+/}$[18], although their mean survival times were identical. Interestingly these mice, but especially $\operatorname{Trp} 53^{R 270 H /+}$ and $\operatorname{Trp} 53^{R 270 H /}$, gave rise to more malignant lung adenocarcinomas, desmoplasia and even metastases which never occur in $\operatorname{Trp}_{53}{ }^{--}$mice. These results suggest that "humanised" Trp53 mutations have a greater impact on lung tumour progression than complete Trp53 loss $[18,19]$. Targeting genes deleted early in human lung tumorigenesis, such as the complete cluster at chromosome 3p21.3, showed that heterozygous deletion for this $370 \mathrm{~kb}$ region showed no obvious predisposition for lung cancer development albeit homozygous deletion caused embryonal lethality [20]. A more specific deletion of candidate tumour suppressor genes on chromosome 3 like RassF1a, FHIT and VHL, showed that $31 \%$ of $\mathrm{RassF} \mathrm{a}^{-/}$mice produced spontaneous mainly lymphomas but also lung adenomas [21]. Treatment of RassF1a $a^{-/-}$mice with $\mathrm{B}[\mathrm{a}] \mathrm{P}$ or urethane resulted in an even higher rate of lung tumours. No spontaneous lung tumours were observed in $\mathrm{Fhit}^{-/-}$or $\mathrm{Vhl}^{+/}$ mice, but $44 \%$ of $\mathrm{Fht}^{-/ /} / \mathrm{Vhl}^{+/-}$mice developed adenocarcinomas by age 2 yrs. Again use of mutagens such as dimethylnitrosamine led to $100 \%$ adenoma and adenocarcinoma induction in $\mathrm{Fhit}^{-/ /} / \mathrm{Vhl}^{+/-}$mice and even adenomas in $40 \%$ of $\mathrm{Fhit}^{-/-}$mice by age 20 months [22]. This showed the usefulness of these knockout mice in recapitulating a pattern of early lung cancer development similar to human pattern.

A different approach to address lung cancer onset was the use of knock-in alleles to activate oncogenes. One example of this is based on the somatic Kras activation via an oncogenic Kras ${ }^{G 12 D}$ 
knock-in allele $\left(\mathrm{Kras}^{\mathrm{LA2}}\right)$, which is expressed only after a spontaneous recombination event (fig. 1) [23]. In this way, sporadic Kras ${ }^{\mathrm{G} 12 \mathrm{D}}$ expression occurred on an endogenous level, which in turn augments efficient development of lung adenocarcinomas. However, these mice also developed other tumour lesions as Kras ${ }^{\mathrm{G} 12 \mathrm{D}}$ expression was not limited to the lung epithelial tissues.

\section{Second generation}

In order to refine the current mouse models, a better method of replicating true expression patterns of oncogenes during lung tumorigenesis had to be taken into account. Furthermore, a general knock-in or knockout procedure only poorly represents genetic events that occur during sporadic lung cancer. Too great an extended expression of dominant oncogenes and/ or inactivation of tumour suppressor genes creates a microenvironment that simply does not correspond to sporadic cancer development in which just a limited amount of tumour cells are surrounded and interact with normal cells [24]. Conditional regulation of the temporal-spatial expression of oncogenes or deletion of tumour suppressor genes in somatic tissues of choice can more accurately mimic the in vivo situation leading to the onset of sporadic cancer (fig. 1). This is why the second generation of mouse models for lung cancer makes use of a conditional bitransgenic tetracycline inducible system [25]. Most often, the reverse tetracycline-controlled transactivator (rtTA) inducible system is used. The first transgene with the rtTA element behind a tissue-specific promoter guaranties the rtTA expression in a cell or tissue type of choice. This transgene is then combined with a second transgene, consisting of a target gene behind a tetracyclineresponsive promoter $\left(\operatorname{Tet}_{7}\right)$. The presence of tetracycline/ doxycycline ensures stable interaction of the rtTA element with the $\mathrm{TetO}_{7}$ promoter, which in turn expresses the target gene.

Therefore, on/off target gene expression is possible depending on administration or withdrawal of tetracycline/doxycycline [26]. Both SP-C-rtTA and CCSP-rtTA transgenes [27] have been used for directing doxycycline responsive rtTA to either alveolar type II or Clara cells. Several bitransgenic mice such as CCSP-rtTA; $\mathrm{TetO}_{7} \mathrm{FGF}-7$ [28] and CCSP-rtTA;TetO $\mathrm{Kras}^{\mathrm{G} 12 \mathrm{D}}$ [29] have been successfully used to induce lung lesions. Induction of FGF-7 caused initial epithelial cell hyperplasia followed by adenomatous hyperplasia after doxycycline application. All hyperplasia disappeared after withdrawal of

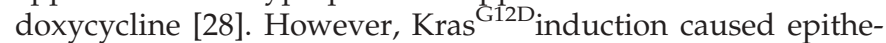
lial cell hyperplasia, adenomatous hyperplasia and, after 2 months doxycycline application, multiple adenomas and adenocarcinomas. Again, no lesions could be detected after 1 month of doxycycline withdrawal [29]. When the CCSPrtTA; $\mathrm{TetO}_{7} \mathrm{Kras}^{\mathrm{G} 12 \mathrm{D}}$ alleles were combined with conventional Trp53 or Ink4a/ARF null alleles, adenocarcinomas with a more malignant phenotype had already appeared after 1 month doxycycline application, thus showing a synergy of mutantKras and both tumour suppressor deficiencies. However, even in these compound Tet-inducible mouse models, all lesions disappeared after doxycycline withdrawal. This showed the importance of mutant-Kras as a "driving" oncogene not only at tumour onset but also during maintenance of adenocarcinoma in these mouse models. Although the histopathological similarities with human adenocarcinomas were quite obvious, no metastases were found to arise from these murine adenocarcinomas [29].

Simulating more complex lung tumour genetics in human lung cancer required an expanded approach with other conditional genetic systems. The Cre/loxP or Flp/FRT system [24, 30] provided excellent tools for this by introducing somatic mutations in a limited number of differentiated cells of choice whereby other cells of the fully developed lung remained normal [23, 31]. In short, mutations of targeted regions, flanked by loxP (also known as being "floxed") or FRT sequence sites, are introduced through deletion by their respective sitespecific recombinases Cre or Flp. Thus, in the case of tumour suppressor genes, conditional hypomorphic mutations or null allele, several (non)coding exons are floxed and can, therefore, be deleted by its corresponding recombinase (fig. 1). Conversely, floxed transcription stops (Lox-Stop-Lox or LSL) in front of oncogene or knock-in alleles can control their respective conditional activation [32]. The determining factor of this conditional approach is the control of temporal-spatial Cre or FRT recombinase expression. For that purpose, several Cre transgenic lines have been generated, with or without Tet inducible promoters [27]. Apart from this, Cre-mediated recombination can also be achieved through the administration of an engineered Adeno-Cre virus via nasal or tracheal instillation [31, 33]. An advantage of the latter method is that a limited amount of adult lung cells can be targeted in a very concise, localised and timely fashion. Efficacy of this method was tested with conditional alleles of $\mathrm{Kras}^{\mathrm{G12D}}$ and $\mathrm{Kras}{ }^{\mathrm{G12V}}$ $[31,33,34]$. Infection of adult lungs with Adeno-Cre virus rapidly resulted in the onset of adenomatous alveolar hyperplasia, followed by the development of adenomas and finally adenocarcinomas at 3-4 months post-infection. Although a latency of 8 months was also observed [34], no metastases could be found in any of the models. Most probably a single Kras activation is not enough to allow the adenocarcinomas to progress into a higher state of malignancy as would be required for fully metastasising lesions. However, these straightforward experiments disclosed the important role of Kras in human lung cancer onset and progression [17, 34]. Another important aspect of this model was that lung tumour multiplicity could be controlled by the dose of Adeno-Cre virus infecting only a subset of lung epithelial cells. This, together with a controlled time-point of Adeno-Cre application, indeed ensures a precise mimicking of the sporadic character of human lung cancer development.

However, one has to be careful to note that variability of the Adeno-Cre virus delivery and infection (especially with the intranasal method) might lead to inconsistent experimental results. Nevertheless this versatile method remains powerful in that it resembles human lung cancer events.

In the next part of our review we want to give an update of most of the recent advances in mouse models for human lung cancer. For this we will focus on the proceedings on the three main types of lung cancer, namely nonsmall cell lung carcinoma (NSCLC), small cell lung carcinoma (SCLC) and squamous cell carcinoma (SCC).

The types of available genetically modified mouse models, causal genotype-phenotypic correlations and implications for 
a)

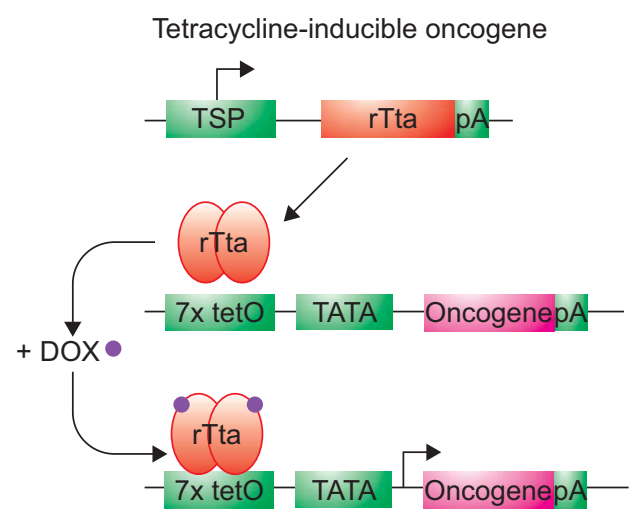

c)

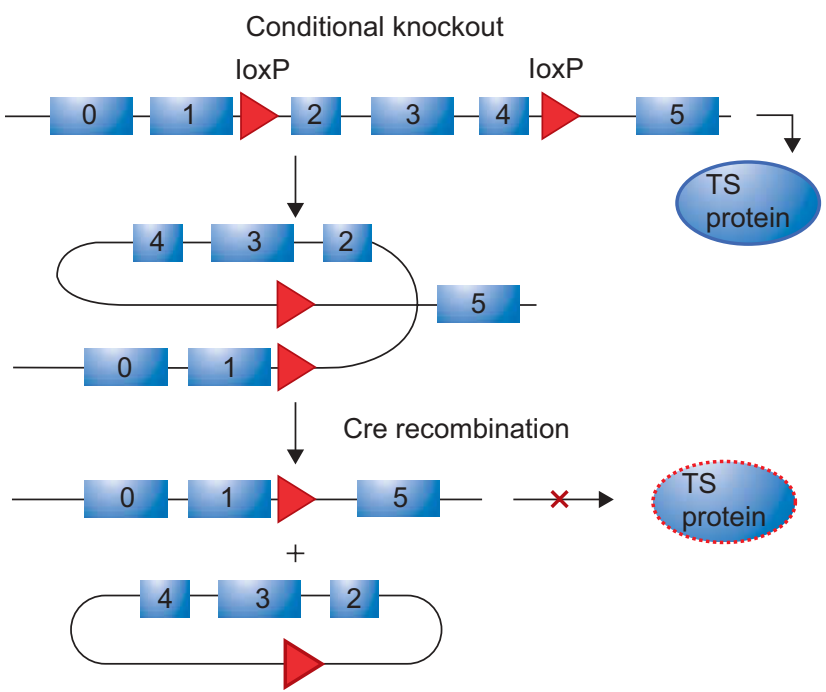

b)

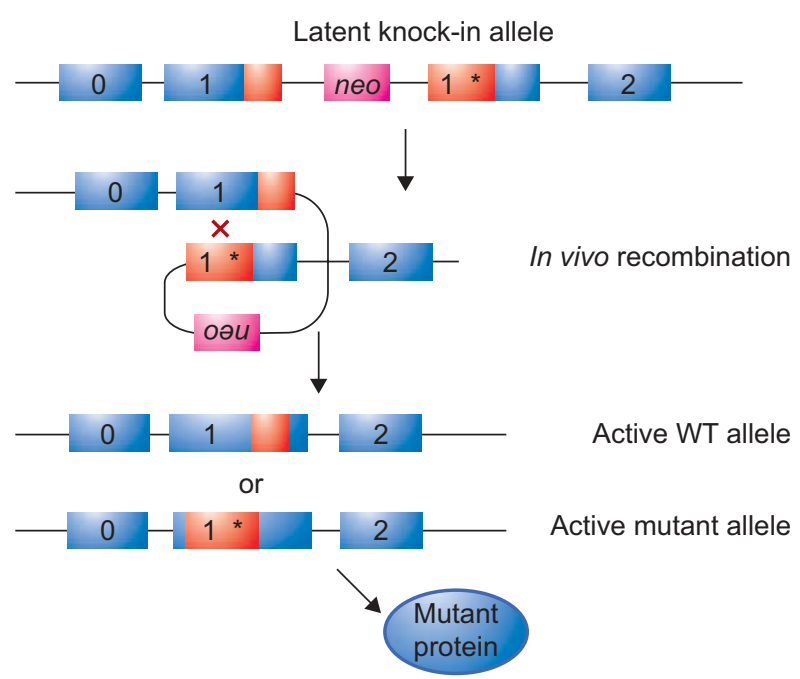

d)

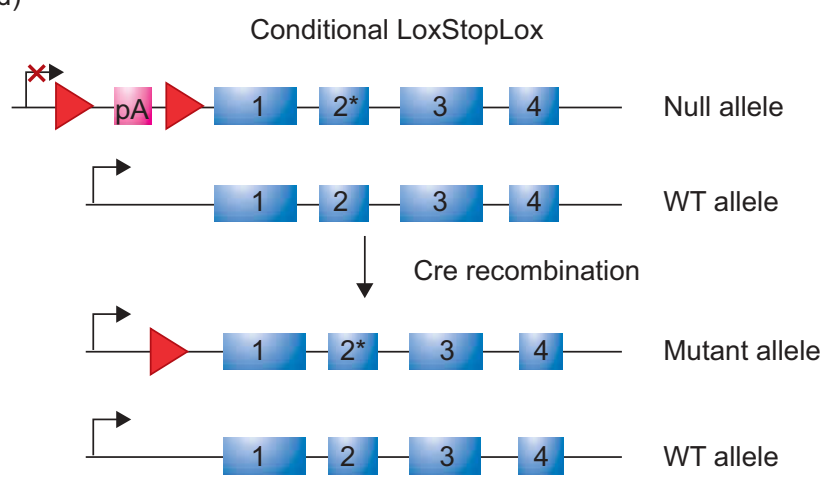

FIGURE 1. Overview of systems used in most of the genetically engineered mouse models for lung cancer. a) The tetracycline-inducible bitransgenic system. A tissuespecific promoter (TSP) drives the expression of a Tet-inducible transactivator (rTTA). In the presence of doxycycline (DOX), rtTA dimers can specifically bind to seven tetO (7x tetO) sequences and activate oncogene transcription from the minimal TATA promoter. b) The latent activated allele ensures stochastic oncogene activation via spontaneous in vivo recombination of a silent mutant allele. A neomycin resistance (neo) gene separates a wild-type (WT) and a mutated copy of the otherwise identical exons. After recombination, only a WT allele or an allele with an activating mutation is left to exert oncogenic functions. c) Conditional gene inactivation is based on Cre/loxP recombination-mediated deletion of one or more exons. Site-specific Cre recombinase induces mutations through recombination of two direct orientated LoxP sequences. Thus, controlling Cre recombinase activity ensures eventual tumour suppressor (TS) gene inactivation into various tissues of choice. d) Conversely, the conditional LoxStopLox allele makes use of a strong transcription stop, flanked by two lox sites, in front of a coding exon. The resulting null alleles can become an oncogenic mutant allele after removal of the transcription stop element via Cre-mediated recombination. pA: polyadenosine.

translational research will be briefly discussed for each of these main lung cancer types.

\section{MODELS FOR NSCLC}

To date, most mouse models generate lung adenocarcinomas with various stages of malignancy. As we have already discussed, a frequently used way of driving lung tumorigenesis is through conditional or spontaneous activating Kras mutations [17]. However, it is obvious that more complex mouse models are needed to further our understanding of highly complicated lung cancer genetics (fig. 2). Validation of these mouse models then requires knowledge of how closely mouse models resemble human lung cancer. Several studies used cross-species comparisons of gene expression profiles between murine and human lung tumours to identify similarities in cancer signalling pathways $[35,36]$. Integration of gene expression data from a Kras ${ }^{\mathrm{LA} 2}$ mouse model and KRAS mutated human lung tumours indeed showed a significant overlap but also revealed a gene-expression signature for Kras mutation in human lung cancer itself [35]. These results presented powerful molecular criteria to assess similarities between mouse and human lung cancer, as well as new possibilities to further elucidate important genes that control less well-characterised lung cancer pathways. Since 
activating Kras mutation models recapitulate some of the human lung tumour phenotypes rather well, closer analyses of early lung tumour initiating events were performed [37, 38]. A combination of both CCSP CC10-Cre recombinase and LSL $\mathrm{Kras}^{\mathrm{G} 12 D}$ alleles [37] resulted in a progressive phenotype of cellular atypia, adenoma and finally adenocarcinoma. These lesions originated exclusively from bronchial epithelia but were accompanied with a strong inflammatory response through expression of various chemokines. Kras activation could, therefore, serve as an excellent model to study the complex interactions between transformed lung epithelial and inflammatory cells, chemokines and early tumour development. Another model for generating early, benign lung tumour lesions makes use of a bitransgenic Tet-inducible Kras ${ }^{G 12 C}$ allele that can be expressed in both Clara and/or alveolar type II cells $[27,38]$. Only mild atypical hyperplasia or benign adenomas were found and even after an induced Kras ${ }^{\mathrm{G} 12 \mathrm{C}}$ expression of $\geqslant 12$ months, no further tumour progression could be detected. Inhibition of Kras ${ }^{\mathrm{G} 12 \mathrm{C}}$ expression through doxycycline withdrawal over 1 month led to a complete reversal of any early proliferative lesion. Thus, both Kras ${ }^{G 12 C}$ and $\mathrm{Kras}^{\mathrm{G} 12 D}$ oncogenes are needed for maintaining a tumour phenotype. One explanation of the low tumour penetrance of Kras ${ }^{G 12 C}$ alleles could be the absence of activation of Akt and JNK signalling pathways. This latter observation was in strong contrast to the effects of the previously described Kras ${ }^{G 12 D}$ models.

It is rather puzzling that Kras but not Hras or Nras mutations are predominantly found in lung carcinomas [39]. A plausible explanation for this can either be that differences in the Ras protein isoforms render them different oncoprotein activities, or differences in their respective gene regulatory elements confer tissue-specific expression to the mutated Ras gene in its corresponding tumour. Moreover, one has to note that the Kras gene encodes two isoforms, $4 \mathrm{~A}$ and $4 \mathrm{~B}$, with differences in their $\mathrm{C}$ terminus. This $\mathrm{C}$ terminus of the predominant Kras $4 \mathrm{~B}$ isoform is prone to exclusive post-translational modifications, such as farnesylation or geranylgeranylation [40]. However, Kras 4A has a post-translational modification that includes covalent attachment of a palmitoyl moiety, as do Hras and Nras. The latter modifications give Nras, Hras and Kras 4A distinct signalling activities by facilitating their localisation in specific microdomains in membranes [41]. A recent elegant study elucidates Kras mutation specificity in lung cancer by exchanging either a Hras or Kras 4B cDNA into the original Kras gene by generating Hras ( $\mathrm{Hras}^{\mathrm{KI}}$ ) or Kras $4 B$ (Kras ${ }^{\mathrm{KI}}$ ) knockin mice. Surprisingly, the number of urethane-induced lung tumours in $\mathrm{Hras}^{K I / K I}$ was much higher compared to Kras ${ }^{K I / K I}$ mice and the latter produced even less tumours than the wildtype (WT) control mice [42]. Interestingly, when mutations were analysed in $\mathrm{Kras}{ }^{\mathrm{KI} / \mathrm{wt}}$ heterozygous mice, they were only detected in the WT allele which expresses Kras 4A, as well as Kras 4B. This led to the conclusion that only a mutated Kras $4 A$ allele, which, after all, shares functional $C$ terminus similarity with Hras, can induce lung tumorigenesis and Kras regulatory elements provide its specificity for pulmonary epithelial cells $[42,43]$. In a different setting, a $\mathrm{Kras}^{\mathrm{LA} 2}$ allele was either combined with WT Kras, Hras or Kras ${ }^{K I}$ alleles. The number of spontaneous lung tumours was high in $\mathrm{Kras}^{\mathrm{LA} 2 / \mathrm{KI}}$, but similarly low in $\mathrm{Kras}^{L A 2 / W T}$ and $\mathrm{Hras}^{K I} ; \mathrm{Kras}^{L A 2}$ mice. This tumour suppressing activity can only be accounted for by an intact WT locus which is capable of encoding an intact Kras 4A isoform and could, therefore, be functionally substituted by a similar $\mathrm{Hras}^{\mathrm{KI}}$ allele [42]. Thus, there is now compelling evidence that a normal WT Kras allele actually inhibits and that preferentially a mutated Kras $4 A$ allele actively induces lung tumorigenesis, respectively, in a strictly tissue specific manner [42-44]. In hindsight, this also explains earlier observations in which vinyl-carbamate treated mice with one Kras $\mathrm{KO}$ allele produced a higher number of more advanced adenocarcinoma than control WT Kras mice [45].

We know that the occurrence of somatic Kras mutations in lung cancer is prevalent [46], thus making the understanding of the precise role of Kras pathway effectors very important (fig. 2).

Indeed, mutations in candidate effectors BRAF and PI3K of activated Ras downstream pathways have been reported in human NSCLC $[47,48]$. Activating mutations of $B R A F$ would most likely have a stimulating effect on mitogen-activated protein kinase $(M A P K)$ pathways. This hypothesis was tested in a lung specific, Tet-inducible, expression of a BRAFV600E mutant transgene [46]. In this mouse model, CCSP-rtTA; TetO $7^{-}$ $B R A F V 600 E$ showed a development of lung adenocarcinoma with bronchioalveolar carcinoma features. The extracellular signal-regulated kinase (ERK)-1/2 (MAPK) pathway was significantly upregulated. Upon doxycycline withdrawal, the BRAF-mutant lung tumours disappeared in combination with a marked decrease in phosphorylation of ERK1/2. Furthermore, the in vivo use of a specific MAPK/ERK kinase (MEK) inhibitor induced lung tumour regression. Interestingly, the latter effect could be reproduced with lung tumours from CCSP-rtTA;Tet $\mathrm{O}_{7}-\mathrm{Kras}^{\mathrm{G} 12 \mathrm{D}}$ mice [46]. All these results showed that both activated BRAF and KRAS signalling convert on the same MAPK pathway, making this pathway a potential target for lung tumour intervention. These results were confirmed by another independent study in which a floxed BRAFV600E allele was activated in lung epithelium via nasal Adeno-Cre delivery [49], which caused a formation of benign adenoma. However, the majority of these latter lesions did not further develop into adenocarcinoma and the abundant nonprogressed adenoma also showed features of oncogene induced senescence. Combining BRAFV600E activation with loss of Trp53 or Ink4a/Arf led, as expected, to marked tumour progression into adenocarcinoma [49]. A close investigation during $\mathrm{Kras}^{\mathrm{G}}{ }^{2 \mathrm{D}}$ driven lung tumorigenesis showed an increased phosphorylation of MAPK during which the MAPK antagonist Sprouty-2 (Spry-2) was upregulated. When Cre/lox dependent Spry-2 $2^{F / F} ; L S L$ Kras ${ }^{G 12 D}$ mice were used for lung tumour induction, a clear increase in both tumour load and development was observed in $\mathrm{Kras}^{\mathrm{G12D}}$;Spry- $2^{-/-}$tumours. This clearly suggested a tumour suppressor activity for Sprouty-2 during Kras dependent lung tumorigenesis by impairment of the Ras/MAPK signalling cascade [50].

Another approach to understand the role of the Ras downstream effector pathway led to the simultaneous Cre/lox dependent deletion of $R a c 1^{F / F}$ in the presence of activated Kras [51]. Results showed a significant delay in Kras dependent adenoma formation in $\mathrm{Racl}^{-/}$versus $\mathrm{Racl}^{+/}$lesions, which suggest that Kras signalling acts, at least in part, through Rac1 during lung tumour development. 


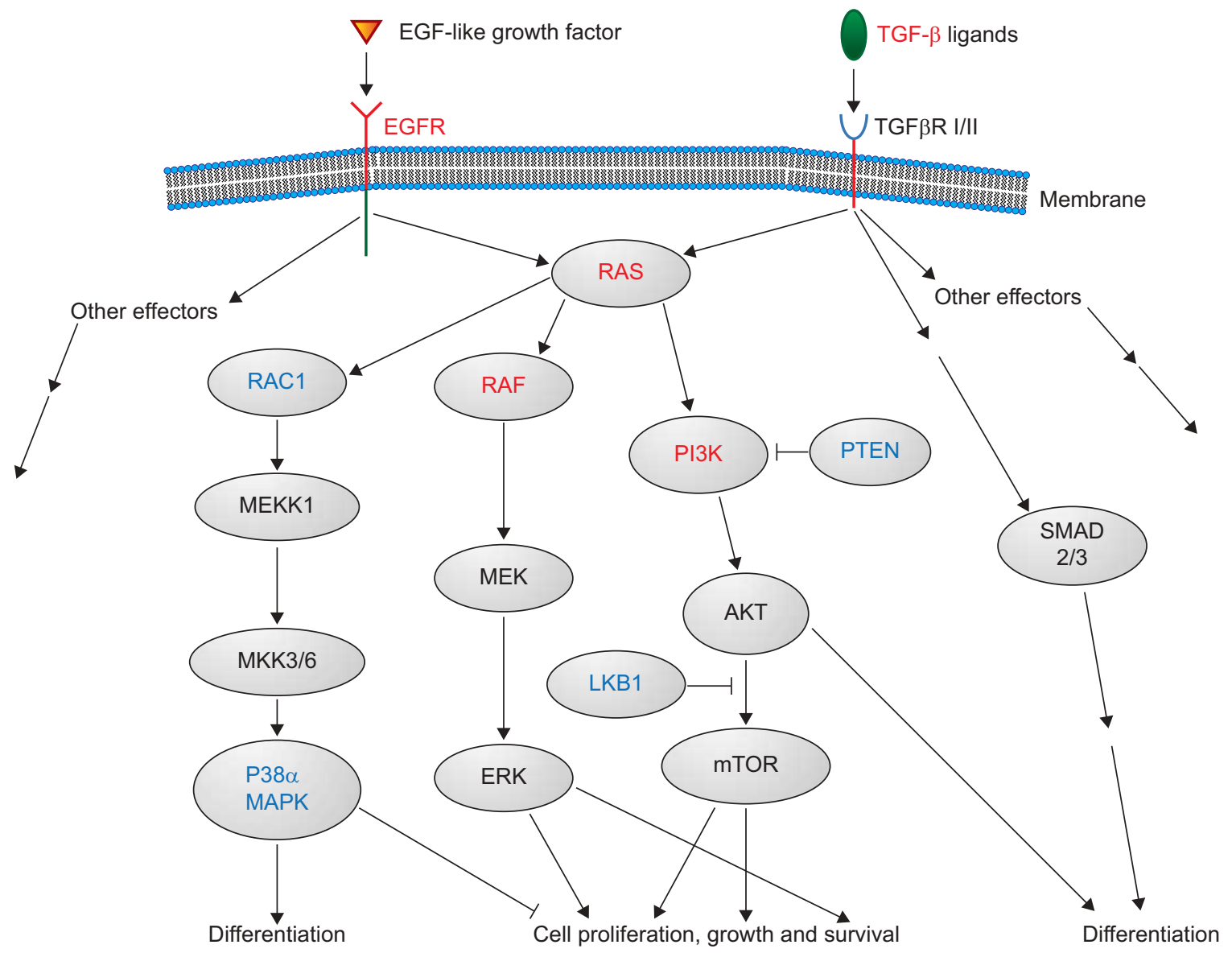

FIGURE 2. Schematic overview of the major signalling pathways that are impaired in most of the nonsmall cell lung cancer models. Activation of the signalling network occurs through activating mutations of the oncogenes (shown in red) or inactivating tumour suppressor genes (shown in blue). At the core of the signalling cascade are RAS (rat sarcoma viral oncogene homologue) and its stimulation of the RAF-MEK-ERK (serine/threonine kinase raf-mitogen-activated protein kinase kinase-extracellular signalregulated kinase kinase) and PI3K (phosphatidylinositol 3-kinase) pathways. Activating mutations in epidermal growth factor receptor (EGFR) serve as the main models for receptor tyrosine kinases upstream of RAS. As for transforming growth factor (TGF)- $\beta$, one has to acknowledge its dual role as a tumour suppressor during the early phase of lung tumorigenesis and a pro-oncogenic factor in more advanced and metastatic lung tumours. Note that RAC1 (Ras-related C3 botulinum toxin substrate 1, small GTPase) exerts oncogenic activity in collaboration with RAS, since inactivating Rac1 models showed an impairment of RAS-driven lung tumorigenesis. EGF: epidermal growth factor; TGF $\beta$ R: TGF- $\beta$ receptor; Mekk1: mitogen activated protein kinase kinase kinase 1 or MAP3K1, serine threonine kinase; Mkk3/6: mitogen-activated protein kinase kinase 3 or MAP2K3, serine threonine kinase; p38 $\alpha$-MAPK: mitogen activated protein kinase p38 $\alpha$ or MAPK14; PTEN: phosphatase and tensin homolog; AKT: serine/threonine kinase also known as protein kinase B; LKB1: serine/threonine kianse LKB1 also known as serine/threonine protein kinase 11, STK11: mTOR: mammalian target of rapamycin, serine/threonine protein kinase; SMAD 2/3: TGF- $\beta$-dependent gene transcription factors.

Another downstream effector (fig. 2), interlinked with RAS signalling pathway, is phosphoinositide-3-kinase (PI3K) and downstream targets, such as the protein kinase Akt. In human NSCLC somatic mutations that activate PI3K have been identified in the $\mathrm{p} 110 \alpha$ catalytic subunit (encoded by PIK3CA) [52]. Furthermore, selective PIK3CA amplification was found in lung squamous cell carcinomas [53]. Therefore, mice were generated with a Tet-inducible expression of $\mathrm{p} 110 \alpha$, with an activating mutation in its kinase domain (H1047R), and then crossed with CC10 promoter-reverse tetracycline transactivator protein (rtTA) to generate CCSP-rtTA;TetO PIK3CA(H1047R) mice. Upon doxycycline dependent induction of PIK3CA(H1047R) for 14 weeks, double transgenic mice developed adenocarcinomas, which subsequently completely disappeared after doxycycline withdrawal for 3 weeks [54]. On the contrary, complete ablation of PI3K activity through deletion of both its p85 regulatory subunits (encoded by
Pik3r1 and Pik3r2) led to a dramatic decrease in the number of lung tumours in LSL Kras ${ }^{G 12 D}$;Pik3r2-/; $\mathrm{Pik3r}^{-/-}$mice [54]. Many in vitro studies showed that Ras proteins directly interact with the $\mathrm{p} 110 \alpha$ subunit of PI3K and introduction of specific mutations in PIK3CA blocks this interaction [55]. In order to study the Rasp110 $\alpha$ interactions in vivo and its effects on tumorigenesis, $\mathrm{Pik}_{3 \mathrm{Ca}^{-/-}}$mice were generated and crossed with $\mathrm{Kras}^{\mathrm{LA2}}$ alleles. These $\mathrm{Pik}_{3 \mathrm{Ca}^{-/}} ; \mathrm{Kras}^{L A 2}$ mice were highly resistant against lung tumour formation, which suggest that Ras-p110 $\alpha$ interaction is needed for Ras-driven tumorigenesis [55].

All these results underline the importance of PI3K signalling not only for lung tumour induction but also maintenance.

Cross talk between Ras-MAPK, transforming growth factor (TGF)- $\beta 1$ and its type II receptor (TGF- $\beta$ RII) does exist [56], while TGF- $\beta 1$ is implicated as a tumour suppressor gene in 
human lung cancer [57]. To test this latter hypothesis in vivo, lung tumorigenesis was followed in $\mathrm{Kras}^{\mathrm{LA}}{ } ; \mathrm{Tgf}-\beta 1^{+/-}$versus $\mathrm{KraS}^{L A 2}$ mice. The Kras ${ }^{L A 2} ; \mathrm{Tgf}-\beta 1^{+/-}$lung tumours appeared faster and with a relatively higher amount of adenocarcinomas compared to those from Kras ${ }^{L A 2}$ mice. Surprisingly, adenocarcinoma that retained WT levels of TGF- $\beta 1$ had significantly higher angiogenic activity than $T g f-\beta 1^{+-}$adenocarcinoma. Therefore, TGF- $\beta 1$ is a bona fide tumour suppressor during onset and progression of lung tumorigenesis, but also needed at the same time for lung tumour-induced angiogenesis and metastatic potential [58].

Another key player driving human NSCLC is EGFR signalling, which is independent and upstream of Kras (fig. 2). In fact, mutations in EGFR occur mutually exclusive from those found in the Kras gene in human NSCLC [48].

Most mutations in EGFR occur around the region encoding the ATP binding pocket of the receptor's tyrosine kinase domain in exons 18-21 [59]. More precisely, these mutations occur as inframe deletion in exon 19, which eliminate a conserved LREA (lysine, arginine, glutamic acid and alanine protein sequence) motif $\left(\mathrm{EGFR}^{\mathrm{DEL}}\right)$, and an L858R substitution in exon 21 [48]. When these specific mutations were engineered in mice by use of the Tet-inducible system, two types of bitransgenic mice were generated: CCSP-rtTA;Tet-O $-h E G F R^{L 858 R}$ and CCSP$r t T A ; T e t-O_{7}-h E G F R^{D E L}$. Both bitransgenic mice expressed mutated human EGFR in lung type II alveolar cells and following a few weeks of doxycycline administration developed bronchioloalveolar carcinomas [60,61]. However, tumour development continued when the doxycycline application period was extended beyond 4 weeks, resulting in the formation of invasive adenocarcinomas. However, when doxycycline was withdrawn the absence of mutated hEGFR resulted in a complete regression of lung cancer [60]. Overall, the tumour phenotype showed a remarkable resemblance with human adenocarcinoma. This makes these bitransgenic models excellent tools for the study of EGFR-dependent NSCLC as it confirms that $h E G F R^{D E L}$ and hEGFR ${ }^{\mathrm{L} 858 \mathrm{R}}$ are dominant oncogenes capable of inducing fully fledged lung cancer. Another distinct EGFR mutation, the variant III (vIII) in-frame deletion of exons 2-7, was found in some $5 \%$ of analysed human squamous cell carcinoma but not in adenocarcinoma [62]. Bitransgenic CCSP-rtTA;Tet $O_{7}-E_{\text {GFR }}{ }^{\text {vIII }}$ mice developed adenocarcinoma after 16 weeks of doxycycline application. Lung tumours depended on EGFRvIII expression as doxycycline withdrawal led to complete tumour regression [62]. All EGFR mutant mouse models showed the importance of EGFR activity in NSCLC and are highly penetrant in producing advanced adenocarcinoma.

Since expression of phosphatase and tensin homologue deleted from chromosome 10 (PTEN) is often down regulated in NSCLC, several mice models were generated in which Pten was inactivated in the bronchial epithelium $[63,64]$. PTEN is a tumour suppressor gene that acts by blocking the PI3K dependent activation of serine-threonine kinase Akt (fig. 1). Since $\mathrm{Pten}^{-/}$mice are embryonal lethal, one had to make use of floxed Pten alleles $\left(\right.$ Pten $\left.^{F / F}\right)$, combined with CCSP-Cre transgene, targeting Pten deletion into bronchial Clara cells. However, these $\mathrm{Pten}^{F / F} ; \mathrm{CCSP}$-Cre mice did not show any aberrant pulmonary development or phenotypic abnormalities even when followed for $\geqslant 12$ months [64]. This changed dramatically when the Pten ${ }^{F / F} ; \mathrm{CCSP}$-Cre alleles were combined with $L S L K$ ras $^{G 12 D}$. Lung tumorigenesis was markedly accelerated compared to that of single LSLKras ${ }^{G 12 D}$ mice. Kras mutant, Pten deficient tumours were often of the more advanced adenocarcinoma type with more vascularity [64], suggesting that Pten loss cooperates with Kras mutations in NSCLC. Contrary to these results were the findings of another study in which Pten inactivation was targeted in bronchioalveolar epithelium with SP-C-rtTA;TetO-Cre [63]. When doxycycline was applied in utero at E10-16 during embryogenesis, most mice died post-natally from hypoxia. Their lungs showed an impaired alveolar epithelial cell differentiation with an overall lung epithelial cell hyperplasia. The few surviving mice developed spontaneous lung adenocarcinomas. Post-natal doxycycline application during P21-27 resulted in a mild bronchiolar and alveolar cell hyperplasia and increased cell size but no lethality. A majority of these animals developed adenocarcinomas in comparison to WT controls. Prior addition of urethane induced an even higher amount of adenocarcinomas. Interestingly, most $\mathrm{Pten}^{-/}$adenocarcinomas (33\%), with or without urethane addition, showed spontaneous Kras mutations. The latter observation again indicates the importance of Kras activity in cooperating with Pten loss during NSCLC development.

Recent studies showed that a large fraction of NSCLC cells had germ line mutations and impaired expression of the LKB1 tumour suppressor gene, a serine threonine kinase also known as STK11 [65]. Mutations in LKB1 are found in Peutz-Jeghers syndrome (PJS) patients and are characterised by intestinal polyps (hamartoma) and increased incidence of epithelial cancers [66]. However, somatic LKB1 mutations have been identified in a minor fraction of these sporadic tumours, such as malignant melanomas, ovaria, breast and pancreatic cancer [67]. An exception of this is formed by lung cancer in which LKB1 inactivation is a common event for NSCLC $[65,68]$. The highest numbers of mutations were found in adenocarcinomas [65] and were significantly more frequent in those adenocarcinomas with KRAS mutations [69]. Interestingly, lung cancer does not have the highest incidence among sporadic cancers in PJS patients [67]. This suggests that loss of LKB1 function might not be the primary genetic event per se which drives lung tumour initiation, but is rather an important facilitating lesion that ensures tumour progression. Results of a study of $L k b 1$ loss in the background of a conditional LSLKras ${ }^{G 12 D}$ dependent in vivo mouse model [70] showed that LKB1 inactivation cooperates with KRAS activation, suggesting a role for LKB1 as an active repressor of the KRAS downstream pathway. Moreover, single $L k b^{F / F}$ mice showed no tumour phenotype. Only $L k b 1^{F / F} / L S L K r a s{ }^{G 12 D}$ mice showed a broad scale of NSCLCs: the majority were adenocarcinoma but unexpectedly SCCs and large cell carcinoma (LCC) also occurred. Furthermore, $61 \%$ of adenocarcinoma progressed into metastases but none were detected for SCC and LCC. Compared to $p 53^{F / F} / L S L K r a s{ }^{G 12 D}$ and (Ink4a/Arf) $)^{F / F} /$ LSLKras $^{G 12 D}$, the $L k b 1^{F / F} /$ LSLKras ${ }^{G 12 D}$ mice had a higher tumour penetration and significant higher number of metastases. In addition, no SCC or LCC were detected in $p 53^{F / F} /$ LSLKras $^{G 12 D}$ and $(\operatorname{Ink} 4 a / A r f)^{F / F} /$ LSLKras ${ }^{G 12 D}$ mice. Results show that LKB1 loss permits squamous differentiation and facilitates metastases but these 
are independent events. Adenocarcinoma from $L k b 1^{F / F} /$ LSLKras ${ }^{G 12 D}$ mice had reduced pAMPK (phosphorylated, adenosyl monophosphate-activated protein kinase) and pACCA (phosphorylated, acetyl-CoA carboxylse $\alpha$-subunit) levels and activated mTOR (mechanistic target of rapamycin protein) pathway (fig. 2). It is probable that LKB1 loss influences differentiation into the NSCLC subtypes via discrete pathways [71]. A large panel of human NSCLC showed LKB1 mutations in adenocarcinoma (34\%), SCC (19\%) and LCC $(16 \%)$ [70]. Concomitant mutations in p53 and LKB1 suggest nonoverlapping roles in NSCLC. Moreover, reconstitution of LKB1 in human NSCLC cell lines showed anti-tumour effects independent of their p53 or (INK4A/ARF) status [70]. Finally, loss of LKB1 expression in alveolar adenomatous hyperplasia, precursor lesion for adenocarcinoma, suggests an early role of LKB1 inactivation during adenocarcinoma development [72].

Not only might direct (epi)genetic mutations in oncogenes and tumour suppressor genes affect their respective expression during lung tumorigenesis, but microRNAs (miRNAs) can also perform similar roles. These miRNAs are classes of small noncoding RNAs that post-transcriptionally regulate the expression of target mRNA transcripts. In order to become active small interfering RNA (siRNA), the primary miRNA transcripts undergo catalytic cleavage by the RNase DICER1. In human lung cancer, increased activities of DICER1 and variant regulations of miRNA clusters have been observed. For the latter, a frequent down regulation of the let-7 miRNA family as well as an upregulation of miR-17-92 has been reported [73]. This miR-17-92 encodes a cluster of seven miRNAs transcribed as single primary transcript. To date, functional analyses of Dicer1 and let-7 have been performed in the background Kras induced NSCLC models. A conditional deletion of Dicer1 in the background of LSLKras ${ }^{G 12 D}$;Dicer1 ${ }^{F / F}$ mice let to a marked increase of tumour development [74]. However, since the $3^{\prime}$ UTR region of Kras transcripts had been shown to be a direct target of let-7 [75], it became especially tempting to increase let-7 expression in Kras ${ }^{G 12 D}$ lung tumours. And indeed, intranasal application of both adenoviral [76] and lentiviral [77] let-7 miRNA caused a severe decrease of $\mathrm{Kras}^{\mathrm{G} 12 D}$; $\mathrm{p5}^{-1-}$ lung tumours. These results showed the potential importance of miRNA regulation for the maintenance of NSCLC.

\section{MODELS FOR SCLC}

Contrary to NSCLC, neuroendocrine carcinomas are virtually never found in spontaneous or chemically induced murine lung cancer. One reason for this could be that in these murine lung cancers a combination of both p53 and $\mathrm{Rb}$ mutations is almost never found, contrary to the majority of human SCLCs. To avoid this, a Cre/lox based deletion of both conditional alleles for $\mathrm{Rb}$ and $\mathrm{p} 53$ was performed by intratracheal instillation with Adeno-Cre [78]. After 3 months, various foci of neuroendocrine hyperplasia developed through the proximal as well as distal bronchi. After a further 3 months, these early lesions progressed into massive lung tumours with typical histological features of SCLC. Interestingly, some early type lesions remained even in the presence of extensive SCLC. Consequently it is of importance to determine if the early neuroendocrine lesions are indeed precursors for SCLC and if so, which additional (epi)genetic events are then needed for them to progress. Immunohistological characterisation of the full-blown tumours revealed that they indeed shared neuroendocrine features with human SCLC. All neuroendocrine differentiation markers, such as calcitonin gene-related protein (CGRP), neuron-specific enolase, synaptophysin, neural cell adhesion molecule and achaete-scute homolog-1 (ASH-1) were not expressed in the same way as in human SCLC. Furthermore, the murine SCLC readily metastasised towards similar organs as found with human SCLC [78]. All primary SCLC, as well as their metastases, had all $\mathrm{Rb}$ and p53 alleles inactivated. Tumours that retained one WT Rb allele were all invariably adenocarcinomas without any neuroendocrine features. Therefore, the status of $\mathrm{Rb}$ most likely determines if tumours do occur with mixed SCLC and NSCLC phenotype, as has also been sometimes observed in patients [79]. No lung tumours could be found in $\mathrm{Rb}^{\mathrm{F} / \mathrm{F}}$ mice, which suggested that loss of $\mathrm{Rb}$ alone is not enough to initiate lung tumorigenesis [78] and the additional loss of p53 is needed.

Not only does $\mathrm{Rb}$ loss need extra genetic events, the nature of these complementary lesions also determines which type of lung cancer will develop. For instance, RB inactivation and Kras mutations are almost never found together in the same human lung cancer. Moreover, the overall mutation rate of RB in human NSCLC is very low [80]. As we have seen already, Adeno-Cre dependent activation of Kras in a broad range of lung epithelial cells leads exclusively to the onset of NSCLC. However, similar application of Adeno-Cre for inactivating RB (and p53) gives completely different neuroendocrine SCLC. Do these results imply then that $\mathrm{Rb}$ loss has no function in Kras driven lung tumorigenesis? Certainly not! When LSLKras ${ }^{G 12 D}$ transgenes were combined with $R b^{F / F}$ and $\mathrm{Rb}$ family $p 130^{F / F}$ alleles for Adeno-Cre dependent lung tumour induction, the results clearly showed much more progressed adenocarcinomas of $\mathrm{Kras}^{\mathrm{G} 12 \mathrm{D}} ; \mathrm{Rb}^{-/} ; \mathrm{p} 130^{-/}$genotypes compared to single $\operatorname{Kras}^{G 12 D}$ [81]. Both Rb loss and p130, albeit to a lesser extent, contributed to Kras dependent NSCLC. Clearly, in this genetic context Kras ${ }^{\mathrm{G} 12 \mathrm{D}}$ overrules any effect of $\mathrm{Rb}$ loss on neuroendocrine differentiation. Another intriguing observation came from $\mathrm{CC}_{10}-\mathrm{rtTA}$; tet $\mathrm{O}_{7}-\mathrm{Cre} ; \mathrm{Rb}^{F / F}$ mice that underwent doxycycline application during early embryogenesis, causing a complete $\mathrm{Rb}$ ablation in all bronchial Clara cells. However, only an increase of hyper cellular neuroendocrine lesions was detected in these mice and no effect on Clara cell homeostasis could be observed. Contrary to this, when all three Rb family proteins ( $\mathrm{Rb}, \mathrm{p} 107$ and $\mathrm{p} 130)$ were inactivated by a truncated SV40 large T-antigen oncoprotein (T121) in CC10-T121 mice, a severe bronchial hyperplasia with complete dedifferentiation of all Clara cells occurred. These results suggested that $\mathrm{Rb}$ might be specifically required for determining neuroendocrine cell fate, but only in a strict cellular and genetic context. All this accumulating evidence from mice models makes it unlikely that NSCLC and SCLC do develop from similar target cells. It would be more plausible that separate, non-identical target cells can develop into different lung cancers, although each still depends on specific major genetic pathways.

Apart from the somatic $R b^{F / F} ; p 53^{F / F}$ model for SCLC, two other lung cancer models have also been associated with pulmonary neuroendocrine tumours. One model made use of bitransgenic CC10-hASH1;CC10-SV40 large $T$ in which progressive neuroendocrine dysplasia and aggressive lung adenocarcinoma develop with both focal neuroendocrine differentiation 
(through expression of pro-neural ASH-1 transcription factor) and CC10 expression [82]. These adenocarcinomas closely resembled human NSCLC with neuroendocrine differentiation [83]. The other model made use of inactivating both cyclindependent kinase inhibitor p18 (Ink4c) and Men1, a tumour suppressor gene deleted in human multiple endocrine neopla-

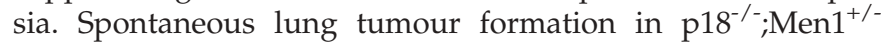
mice initially led to adenoma formation which steadily grew, after a long latency period of $>1 \mathrm{yr}$, into mixtures of both adenocarcinoma and neuroendocrine carcinomas [84]. These mixed lung tumours were, however, distinct from those that developed in $\mathrm{Kras}^{\mathrm{G} 12 \mathrm{D}}$ through their neuroendocrine differentiation. And finally, compared with $\mathrm{Rb}^{\mathrm{F} / \mathrm{F}} ; \mathrm{p} 53^{\mathrm{F} / \mathrm{F}}$ mice these lung tumours lacked the typical histology and metastatic pattern of SCLC.

\section{MODELS FOR SCC}

Human lung SCC is closely linked with smoking and shows a distinct sequence of pre-malignant changes in the airway epithelium from hyperplasia, metaplasia, dysplasia and carcinoma in situ towards complete invasive SCC [85]. However, normal human or mouse lungs do not contain squamous epithelium. Only under pathological conditions does squamous differentiation (accompanied by high expression levels of keratins such as keratin 14 (K14)) occur in epithelium of conducting airways [86]. This explains why spontaneous SCC virtually never occurs in mice and only a few mouse models reported the onset of SCC, mostly after carcinogen application. The latter models use either intratracheal intubation of methyl carbamate [87] or extensive topical application of $\mathrm{N}$-nitroso-methyl-bis-chloroethylurea and $\mathrm{N}$ nitroso-tris-chloroethylurea [88, 89]. The whole spectrum of abnormal squamous phenotypes were observed, but only in susceptible inbred mice (NIH Swiss, A/J, Balb/cJ, FVB/J and SWR/J) and not in others (C57BL/6J, AKR/J and 129/svJ) [89]. Besides, specific loci for SCC susceptibility could be identified through linkage analyses in several mice strains [89]. Another study reported a complete different approach for trying to induce SCC through constitutive expression of human K14 via CC10-hK14 mice [90]. Although CC10-hK14 mice had a FVB/J background and hK14 was readily expressed in bronchial epithelium, only precursor lesions varying from hyperplasia to squamous metaplasia could be observed [90]. Clearly, the increased K14 expression and onset of squamous differentiation alone is not sufficient to generate fully advanced SCC. However, as we have already described, so far only the LSLKras ${ }^{G 12 D} ; L k b 1^{F / F}$ somatic mouse model for NSCLC has been able to generate advanced SCC. LKB1 inactivation results in aggressive and metastatic tumours of which up to $60 \%$ have squamous or mixed squamous histology [70], even though precursor lesions were not found in the conducting airways.

\section{MOUSE MODELS IN TRANSLATIONAL LUNG CANCER THERAPY RESEARCH}

Xenograft models have been extensively used for pre-clinical testing of lung cancer therapeutics. This has mostly been performed on human lung cancer cell lines after they had been subcutaneously injected into immunodeficient mice. The more preferred method, however, would be orthotopical transplantation of human lung tumour cells in their natural pulmonary environment. The results to date show that xenograft models have a poor record of accurately predicting the clinical efficacy of anti-tumour drugs. Therefore, a justified question arises as to whether spontaneous and genetically engineered mouse models for lung cancer would be more useful as tools for preclinical drug tests. It is obvious that there are differences in lung physiology between mice and humans, but some of the mouse models that we have already described have a striking phenotypical resemblance, combined with a genetic signature very similar to human NSCLC [35] and SCLC [91]. Importantly, genetically engineered mouse model-derived tumours develop in an innate immune environment and, therefore, use all the tumour-stromal interactions, such as angiogenesis and degradation of the tissue matrix.

Indeed, the first reports have now been published that show very promising predictive capacity of murine lung tumour models in therapy research and we will discuss two of these now.

However, first we want to briefly address some of the findings from studies in $\mathrm{A} / \mathrm{J}$ mice susceptible for carcinogen-induced lung tumorigenesis. The use of standardised carcinogeninduction protocols in $\mathrm{A} / \mathrm{J}$ mice generates a highly reproducible amount of well-defined lung adenocarcinoma [92]. Therefore, A/J mice are widely used to test the efficacy of chemo-intervention. For example, a $50-60 \%$ tumour mass reduction of adenocarcinomas was obtained after treatment with cis-platinumin combination with metoclopramide and/or indomethacin, while adenoma growth was not affected [93]. Since strain A/J lung tumour models have proved their utility for testing chemotherapeutics, they have also been widely used for evaluating chemoprevention protocols [94]. A broad range of chemopreventive agents, such as farnesyl transferase inhibitors, isothyocynates, nonsteroidal anti-inflammatory drugs and glucocorticoids, as well as natural products like green tea and carotene are just some examples of what has been tested so far [95]. At best, lung tumour growth was impaired by up to 50-60\% [94]. Introduction of p53 and $p 16^{\text {ink } 4 a} / p 19^{A R F}$ mutant alleles into strain A/J mice caused, as expected, a higher lung tumour penetrance but not a dramatic difference on chemoprevention sensitivity [96]. In order to unravel some of the undoubtedly complex genetic traits that cause a chemopreventive effect in the A/J strains, first the genetic signatures for such chemopreventive agents as green tea and budenoside have been established using gene expression arrays $[97,98]$.

We already described two models for NSCLC in which either the continuous oncogenic activity of Kras [29] or EGFR [61] are prerequisites of tumour maintenance. This not only shows that tumour growth critically depends on the respective active oncogenic pathways, but it also stresses the usefulness of these oncogenic pathways as therapeutic targets. Direct tumour intervention studies with tyrosine kinase inhibitors (TKIs) against EGFR mutations proved to be highly effective in several hEGFR transgenic mouse models. TKIs such as gefitinib, erlotinib and HKI-272 led to complete tumour regression [60-62]. In addition, prolonged treatment with humanised anti-hEGFR antibody (cetuximab) caused a strong tumour regression [60]. Further studies will be needed to investigate the pathways that determine sensitivity and resistance to EGFR related TKI interventions. Other mouse 
models for NSCLC were also used for targeted therapies. First, induced over expression of the PI3K p110 $\alpha$ catalytic subunit (PIK3CA), mutated in its kinase domain (H1047R) in CCSPrtTA; $\mathrm{TetO}_{7}$ PIK3CA(H1047R) mice, induces adenocarcinomas. Treatment of these lung tumours with NVP-BEZ235, a dual pan-PI3K and mammalian target of rapamycin (mTOR) inhibitor, caused a marked lung tumour regression. Interestingly, when this single agent NVP6-BEZ235 was tested on lung tumours in CCSP-rtTA; TetO $\mathrm{O}_{7}-\mathrm{Kras}^{\mathrm{G} 12 \mathrm{D}}$ mice, no regression was observed. However, after NVP-BEZ235 was combined with MEK inhibitor ARRY-142886, significant regression of $\mathrm{Kras}^{\mathrm{G}}{ }^{2 D}$ tumours occurred [54]. Obviously, two major RAS (rat sarcoma viral oncogene homolog protein) downstream effector pathways (fig. 2) need to be impaired in order to get an irreversible regression in Ras mutated NSCLC.

Direct targeting of RAS has so far been widely unsuccessful for lung cancer therapy. Many small molecules against Ras functions have been tested and farnesyl transferase inhibitors are the most marked examples of these failed attempts [99, 100]. An explanation for this can possibly be found in the fact that only KRAS4B is farnesylated but not its isoform KRAS4A. Recent results with lung cancer mouse models, as we already described previously, strongly suggest that actually KRAS4A and not KRAS4B is driving the onset of NSCLC. Although we still have to see if KRAS4A is indeed important in human NSCLC, one can imagine the importance of Kras mouse models in testing functional inhibition of KRAS4A [42].

The use of optimised genetically modified mouse models for lung cancer for therapy research necessitates sophisticated noninvasive tools to follow tumour development and response to therapy. Measurement of tumour size as a function of time is the most obvious way of doing this and existing techniques such as positron emission tomography-computed tomography or magnetic resonance imaging are adapted for use on small animals [54,61]. However, these techniques are time consuming, making them less suitable for high throughput. Other sensitive and reproducible techniques are now being widely used for measuring gene expression or tumour growth in vivo: fluorescence imaging and bioluminescence [101, 102]. Expression of fluorescent proteins can be coupled to oncogenes in transgenic mouse models which facilitates fluorescent imaging of tumour growth. In case of bioluminescence, transgenic expression of luciferase allows accurate longitudinal monitoring and good quantification of tumour mass as has been shown in the LSL Kras lung tumour model [103]. Feasible imaging techniques will greatly enhance the accuracy and reproducibility of mouse models.

We have shown some of the promising applications of mouse models in therapy research. However, one should not forget that mouse transgenic models are rather simplistic approximations of the human disease, although some of the somatic models do have a striking resemblance to human lung cancer. Lung tumours in mouse models are often driven by limited and defined pathways on which they remain dependent. Whether human lung cancers show similar dependencies on a continued activity of initiating oncogenes remains to be seen. The strength of genetic engineered mouse models is that it can give us insight into the importance of such particular genetic lesions on tumour growth in a therapeutic setting. As such, it can be a valuable first step in more efficient pre-clinical therapy research.

\section{STEM CELLS AT THE ORIGIN OF LUNG CANCER}

Initial mutated cells undergo a series of various genetic alterations before they finally acquire full tumorigenic capacity [104]. Different early stages of tumour development have been identified for human squamous carcinoma and adenocarcinoma [6], which suggested that transformed bronchial and alveolar cells themselves can serve as cells of origin for lung cancer. As we have shown, this has been confirmed for most, but not all, genetically engineered mouse models for lung cancer. Results from NSCLC as well as SCLC models [70, 78, 81 indicated that both distinct types of genetic mutations and the cell-type in which these lesions occur control initial events of lung cancer development. However, no certainty exists about the nature of cells of origin for lung cancer. Knowledge of these cells can have an important impact, not only on our understanding of lung cancer biology but also by offering us new targets for lung cancer therapies. For many years it has been known that human lung cancer of both adenocarcinoma and SCLC contain small populations of cells $(<1 \%)$ that are able to form colonies in soft agar [105]. Upon transplantation into athymic nude mice, selected soft agar colonies were shown to generate tumours with similar features of the original primary lung cancers [105]. Therefore, human lung cancer clearly consists of heterogeneous cell types of which only a small subset can fully renew the tumour. It is tempting to classify the regenerative or clonogenic subset of lung cancer cells as "cancer stem cells" (CSC). Being a CSC would imply that they share features or are directly derived from mutated, transformed normal stem cells. So what are the features of normal stem cells that make them such ideal tumorigenic targets? Stem cells are defined as rare, long-lived cells whose main properties include self-renewal capacity, extensive proliferation via transit-amplifying cells, and multipotent capacity through generation of mature, terminally differentiated cells [106, 107]. Self-renewal allows maintenance of an undifferentiated stem-cell pool over the lifetime of the host and together with its longevity makes CSCs ideal candidates for accumulating sufficient genetic lesions needed to initiate tumorigenesis. Multidrug-resistance is an additional property of normal stem cells, which secures their longevity in the face of toxic agents, including many of the well-known drugs used in lung cancer therapy. Functional multidrug-resistance is often mediated by over expression of adenosine triphosphatebinding cassette (ABC) transporter that efflux drugs [108]. Indeed, over expression of $A B C$ transporters have been described in clonogenic subsets and are a probable cause for chemoresistance of the treated tumours [108]. The latter observation could also be of particular interest for human lung cancer since recurrence after chemotherapy and radiotherapy is common in human lung cancer [109]. A defined chemoresistant CSC population could be a potential source of tumour recurrence and thus become in itself a valuable therapeutic target.

However, only recently have similarities between cancer cells and normal stem cells led to the idea of the presence inside epithelial tumours of a small population of CSC or "tumourinitiating cells" [108]. CSCs are defined as a rare population of 
undifferentiated tumorigenic cells responsible for tumour initiation, maintenance and spreading [106, 108]. These cells have been identified in many types of cancers by sorting cell subpopulations based on surface marker expression patterns, and by transplantation studies into animal models using prospectively isolated tumour cells. Their existence was first documented in the context of leukaemia [110, 111]. Following this, they have been identified in breast cancer [112] and glioblastoma [113]. Lately, "tumour initiating cells" have been identified in a wide variety of tumours including prostate, colon, pancreatic and hepatic carcinomas, melanoma and several other tumour types [114]. These studies have shown that these cells present an unlimited renewal potential and that they can undergo differentiation leading to the formation of tumours in immunodeficient mice that recapitulate the heterogeneity of the original tumour at high efficiency [115]. Nevertheless, at present it is still not clear whether CSCs exist inside a solid tumour. However, another possibility for the ontogeny of cancer is the so-called stochastic model. This model foresees the onset and progression of cancer from multiple transformed progenitor cells leading to a polyclonal tumour, in which each individual subclone can, in principle, reconstitute a complete tumour [116]. Thus, the latter model predicts that each transformed, undifferentiated cell has the same tumorigenic capacity and the tumour will comprise of a selection of the most dominant subclones [117]. A relative high percentage of cells from a single tumour should, therefore, be able develop into full-blown cancer after xenotransplantation in immunodeficient mice [118].

Thus, there is evidence of distinct lung cancer cell populations and this necessitates a better understanding of how normal bronchial and alveolar tissues are organised in order to identify lung stem cells.

Formation and renewal of lung tissue is largely endogenous as it is now generally accepted that the formation of lung epithelium by circulating mesenchymal progenitor cells is infrequent and not of physiological relevance [119]. Stem-cell research has progressed rather slowly in the lung compared to other organs due to the anatomical and functional complexities associated with cellular heterogeneity and the low turnover rate of its epithelium. Only after being challenged by environmental and nutritional factors does the lung epithelium show a dramatic increase in its turnover rate. This is in contradiction to the constant rapidly renewing tissues of intestinal and haematopoietic origin. These fast renewing tissues have a classical hierarchical organisation of stem cells, and transit-amplifying progenitors and their differentiated progeny. The pulmonary system, however, contains a variety of nonclassical organised transit-amplifying cells, (facultative) progenitor cells and terminal differentiated cells that are anatomically separated in the conducting airway epithelium and gas-exchange alveolar regions [120]. These different pulmonary epithelial cells were mainly identified by airway injury experiments. Various toxic agents were used to trigger the selective damage response of particular lung epithelial cells after which their increased proliferation rates were followed in vivo through $\left[{ }^{3} \mathrm{H}\right]$ thymidine or bromodesoxyuridine (BrdU). In pulse/chase experiments, only self-renewing stem cells retain the label for an extended period due to slow turnover and are so-called label retaining cells (LRCs).
Although the distal epithelium of the lung is composed of Clara, ciliated and neuroendocrine cells, only $\left[{ }^{3} \mathrm{H}\right]$ labelled Clara-like cells were found to be able to proliferate and generate de novo differentiated Clara cells and ciliated cells after exposure with ozone gas had initially damaged all ciliated cells [121]. This provided evidence that Clara cells are facultative progenitor cells, but it did not provide evidence for a stem cell hierarchy within the Clara-cell population. Another toxic agent, naphthalene, induces ablation of almost all nonciliated bronchiolar epithelial Clara cells due to selective metabolic activation of the toxin. This treatment results in the proliferation of two different populations of LRCs in regions localised to neuroendocrine bodies (NEBs) in the distal airway, namely Clara-like cells expressing CC10 and pulmonary neuroendocrine cells (PNECs) expressing CGRP [122]. Both naphthalene-resistant Clara-like cells (named variant or vClara cells) and the PNECs are able to maintain epithelial renewal and their localisation in NEBs is believed to represent a stemcell niche [123-125]. vClara cells are resistant to naphthalene injury because they do not express the enzyme Cyp2f2, which is a member of the cytochrome P450 family that converts naphthalene into a toxic compound. Besides this, vClara cells are also able to efflux drug via multidrug-resistant receptors and present a side population phenotype [126].

A transgenic mouse model in which the herpes simplex virus thymidine kinase (TK) gene is expressed under the control of the CC10 promoter (CC10-TK) was used to test whether PNECs or vClara populations represent the stem cell pool with pluripotent capacity for airway epithelial repair [127]. In this model the CC10-expressing (e.g. both vClara and normal Clara) cells can be selectively ablated in the airways of mice through acute administration of ganciclovir. Studies on the regenerating epithelium showed that the ablation of CC10-expressing cells led to PNEC proliferation and hyperplasia but they are unable to effectively repopulate a differentiated ciliated epithelium [127]. PNEC hyperplasia independent of NEBassociated vClara cells may represent a compensatory mechanism to repopulate the airway in the setting of total stem-cell ablation [128]. Hence, these studies lead to the conclusion that either a subpopulation of CC10-expressing cells, but not PNECs, may represent stem cells required for repair of Clara cell injury in the mouse distal airway or that these cells may be required to support the stem cells that give rise to new Clara cells [127].

A second epithelial stem-cell niche has been identified after similar naphthalene treatment [123, 129]. An LRC subpopulation of Clara cells was found near terminal bronchi, at the bronchioalveolar duct junction (BADJs) where airways terminate and form alveoli and only very few NEBs are observed $[123,124]$. These cells have been termed bronchioalveolar stem cells (BASCs) [129]. They co-express CC10 and SP-C, which is a major secreted compound of type II alveolar cells but expressed at low levels by early embryonic lung epithelial cells [130]. However, dual expressing CC10/SP-C cells were not found in late embryonal lungs, so it is likely that these BASCs develop after birth in rapidly expanding pulmonary epithelial tissue.

This double positive (CC10 and SP-C) population is quiescent in normal lung [131]. BASCs were found to express cell surface 
TABLE 1 Genetically engineered mouse models for human lung cancer

Model type

\section{Transgenic \\ CC10-Tag and Sp-C-Tag \\ $\mathrm{K} 5-\mathrm{E} 6 / \mathrm{E} 7^{\#}$ \\ MMTV-TGF- $\beta 1$ DN" \\ MMTV-RAR $\beta 4^{+}$ \\ CC10-Tag: CC10-hASH1 \\ CC10-hASH1 \\ CC10-hK14 \\ Sp-C-lgEGF \\ Sp-C-cMyc; SpC-IgEGF \\ Sp-C-cMyc \\ Sp-C-cRaf-1 \\ MMTV-RAR $\beta 2^{\S}$ \\ CC10-cMyc \\ CGRP-H-Ras \\ Conditional transgenic}

Using Cre/lox system ${ }^{f} \beta$-actin-lox GFP lox-K Ras ${ }^{\mathrm{V} 12}$-IRES-hPLAP Lox-stop-lox-K Ras G12D\#\#

\section{Doxycycline regulatable}

CC10-rtTA; $\left(\right.$ tetO $\left._{7}\right)$ CMV-FGF7

CC10-rtTA; $\left(\right.$ tetO $\left._{7}\right)$ CMV-K Ras ${ }^{\text {G12D }}$

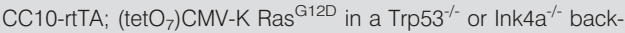
ground

CCSP-rtTA; $\mathrm{TetO}_{7} \mathrm{PIK} 3 \mathrm{CA}(\mathrm{H} 1047 \mathrm{R})$

CCSP-rtTA; TetO $_{7}$-BRAFV600E

SP-C-rtTA; TetO7-Cre; Pten F/F

CCSP-rtTA; Tet-O 7 -hEGFR ${ }^{\text {L858R }}$

CCSP-rtTA; Tet-O ${ }_{7}$-hEGFR ${ }^{\text {DEL }}$

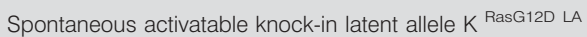

K Ras ${ }^{\mathrm{G} 12 \mathrm{D}} \mathrm{LA}$ in $\operatorname{Trp}^{2} 3^{-/-}$background

K Ras ${ }^{\text {G12D LA; }}$ TGF- $\beta^{+/}$

Conditional knockout

Using Cre/lox system

Trp53

RbF/F; Trp53 F/F

Compound conditional knock out and transgenes

Spry-2 $^{\text {F/F }}$ : LSLKras ${ }^{\text {G12D }}$

Rac1 $^{\text {F/F; }}$ LSLKras $^{\text {G12D }}$

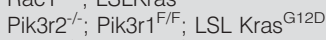

Dicer $^{F / F} ;$ LSLKras $^{\text {G12D }}$

$\operatorname{Trp53}^{\text {F/F; }}$ LSLKras $^{\text {G12D }}$

Trp53 LSL R172H/-; LSLKras $^{\text {G12D }}$

Trp53 ${ }^{\text {LSL R270H/-; }}$ LSLKras $^{\text {G12D }}$

$\mathrm{Lkb}^{\mathrm{F} / \mathrm{F}}{ }^{\text {; LSLKras }}{ }^{\mathrm{G} 12 \mathrm{D}}$

CC10-Cre; PtenF/F; LSLKras ${ }^{\mathrm{G} 12 \mathrm{D}}$

$\mathrm{Rb}^{\mathrm{F} / \mathrm{F}} ; \mathrm{p} 130^{\mathrm{F} / \mathrm{F}} ;$ LSLKras $^{\mathrm{G} 12 \mathrm{D}}$
Multifocal bronchioloalveolar hyperplasias develop into mixed solid and papillary adenocarcinomas

Adenocarcinomas

Adenocarcinomas

Alveolar hyperplasia

Adenocarcinomas with focal NE differentiation

Bronchial hyperplasia

Squamous differentiation hyperplasia with occasional squamous metaplasia

Alveolar hyperplasia

Bronchioloalvealor adenocarcinomas

Mixed bronchioloalveolar adenomas and adenocarcinomas

Adenomas

Adenomas and adenocarcinomas

Bronchioloalveolar hyperplasia

NE hyperplasia and non-NE adenocarcinomas

[143]

[144]

[145]

[82]

[146]

[90]

[147]

[147]

[147]

[148]

[149]

[14]

[150]

Alveolar hyperplasia, adenomas and adenocarcinomas

Epithelial hyperplasia of bronchioles, adenomatous hyperplasia, adenomas, both solid and papillary adenocarcinomas

Epithelial cell hyperplasia and adenomatous hyperplasia

Bronchogenic adenocarcinomas. Phenotype is completely reversible upon Dox removal

Bronchogenic adenocarcinomas. Phenotype is completely reversible upon Dox removal

Adenocarcinomas

Mixed adenocarcinoma and bronchioalveolar carcinoma

Impaired alveolar epithelial differentiation and hyperplasia

Adenocarcinoma with bronchioalveolar carcinoma features

Local invasive adenocarcinoma after longer incubation

Adenocarcinoma with bronchioalveolar carcinoma features

Local invasive adenocarcinoma after longer incubation but with longer latency

Epithelial hyperplasia of bronchioles, adenomatous hyperplasia, adenomas, both solid and papillary adenocarcinomas

Epithelial hyperplasia of bronchioles, adenomatous hyperplasia, adenomas, both solid and papillary adenocarcinomas above but with shorter latency

Increase of adenocarcinoma formation

NE hyperplasia, SCLC with metastases

Phenotypes compared with LSLKrasG12D control

Increased number of adenocarcinoma

Adenoma formation with long latency

Strong decrease of adenoma and adenocarcinoma formation

Increased number of adenocarcinoma

Progressed adenocarcinoma with lymph node metastases

Idem

Idem but with higher penetrance

Shorter latency with mixed adenocarcinoma/squamous cell carcinoma with occasional large cell carcinoma; frequent metastases

Bronchioalveolar lesions followed by adenocarcinoma with local invasion and stromal interactions

Shorter latency and higher number of adenocarcinoma

No neuroendocrine tumours
$[50$

$[51]$

[54]

$[74]$

[151]

[151]

[151]

[70]

[64]

[81]

TGF: transforming growth factor; RAR: retinoic acid receptor; Ig: immunoglobuling; EGF: epidermal growth factor; NE: neuroendocrine; Dox: doxycycline; SCLC: small cell lung cancer. ${ }^{\#}$ : E6/E7 fusion protein was generated; ${ }^{\natural}$ : dominant-negative form of TGF- $\beta 1 ;{ }^{+}$: RAR $\beta 4$ giving sense transcript; ${ }^{\S}$ : RAR $\beta 2$ giving antisense transcript; ${ }^{f}$ : sporadic inactivation of the conditional alleles occurred after intratracheal instillation of Ad-Cre virus; ${ }^{\# \#}$ : intranasal application of Ad-Cre virus.

marker Sca-1 and CD34, which are established stem-cell surface markers in other mouse tissues [132]. Viable (Sca-1+, CD34+) BASCs were able to be isolated by flow cytometry after excluding haematopoietic (CD45+) and endothelial (CD31+) cells [129]. They appear to be crucial for the regeneration of epithelial components of terminal bronchioles and alveoli. Moreover, BASCs are capable of several passages in vitro while either maintaining their $(\mathrm{CC} 10+/ \mathrm{SP}-\mathrm{C}+)$ status or developing into Clara (CC10+/SP-C-), alveolar type II (CC10-/SP-C+) or alveolar type I (SP-C+/aquaporin5 +) cells. Thus, BASCs were shown to be capable of multipotent differentiation as well as self-renewal. At present, we still do not whether these cells function as true stem cells as the evidence for their self-renewal and multipotency in vivo is, as yet, preliminary. Clearly better characterisation of BASCs is needed to identify more unique surface markers, as has been shown by several isolation studies $[133,134]$ but also to investigate how similar or identical vClara cells and BASCs are to each other. Indeed, all the 

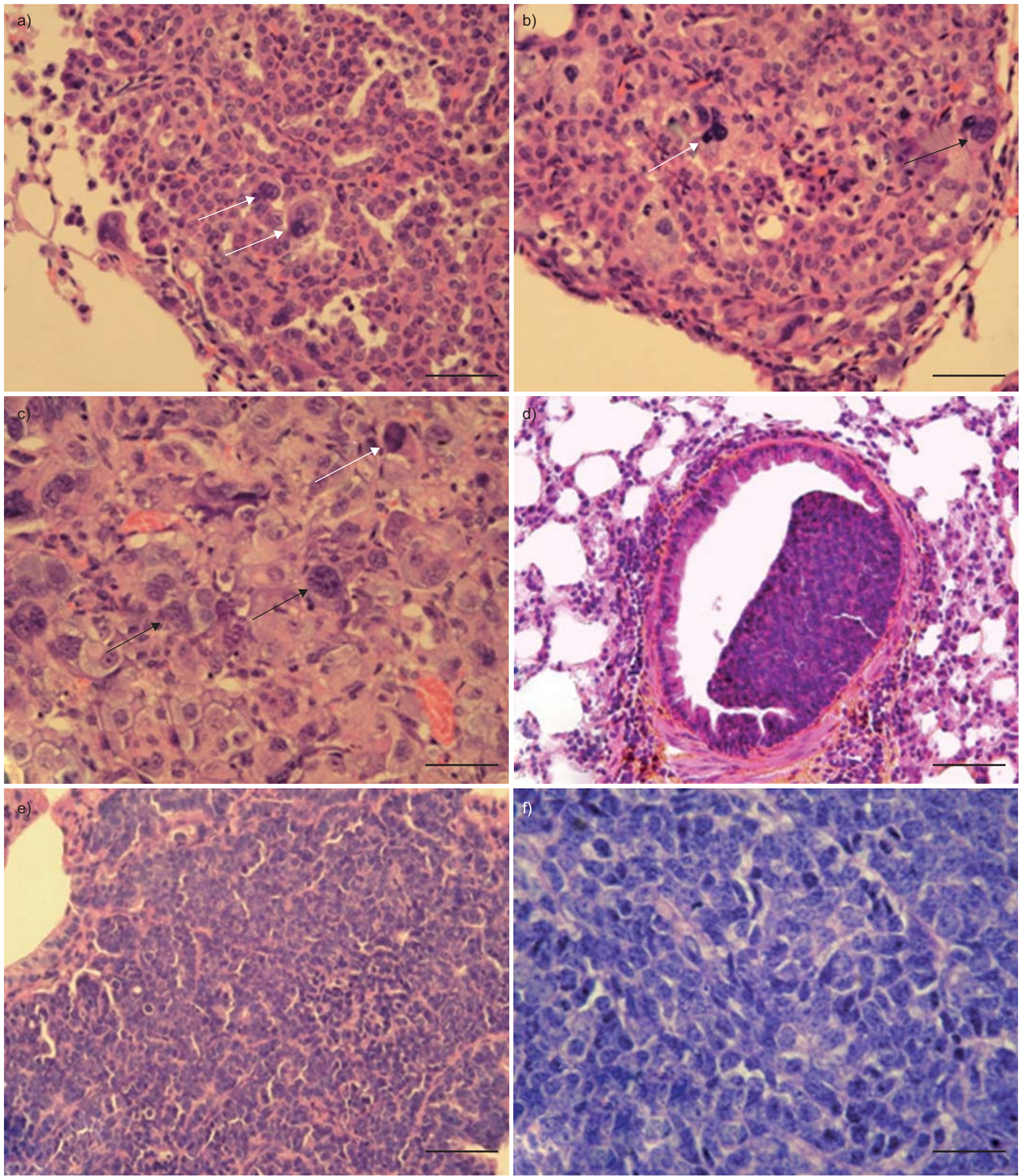

FIGURE 3. Representative lung tumours from mouse models for advanced nonsmall cell lung cancer and small cell lung cancer. The progressed adenocarcinoma from $\operatorname{Trp53}^{\mathrm{FIF} ; \text {;SLKras }}{ }^{\mathrm{G} 12 \mathrm{~V}}$ mice 3 months after Adeno-Cre treatment are shown (a-C; unpublished data). a) Adenocarcinoma in which some tumour cells have irregular nuclei (arrows). b, c) Further advanced adenocarcinoma showing tumour cells with pleiomorphic nuclei (white arrows) and giant cells (black arrows). d) Early neuroendocrine hyperplastic lesions inside bronchi of $R b^{F / F} ; \operatorname{Trp} 53^{F / F}$ mice 3 months after Adeno-Cre treatment which, after a further 3 months, progressed into small cell lung cancer (e, f). Note the characteristic moulding of nuclei of adjacent tumour cells and the sparse amount of cytoplasm. Haematoxin and eosin stain. a, b, d, e) Scale bars=25 $\mu \mathrm{m}$. c, f) Scale bars $=10 \mu \mathrm{m}$. 
evidence so far indicates that both vClara and BASCs are candidates for bronchial stem cells and normal Clara cells are facultative transit-amplifying cells.

Another putative lung stem-cell population was found through the use of a serum-free culture system for primary neonatal pulmonary cells. The arising colonies were positive for CC10 and Sca-1 but negative for SP-C and CD34. In addition, cells were found to express octamer-binding transcription factor 4 (Oct4) and stage-specific embryonic antigen-1. BrdU pulse-chase experiments indicated that slowcycling label retaining Oct4 positive cells are localised at the BADJ [135]. These Oct4 positive cells were able to differentiate into both alveolar type 2 or 1 cells. Again it remains to be seen which similarities this candidate bronchial stem cell shares with the other two candidates. Studies on the finding of CSC in human lung cancer were mostly directed on isolating distinct cell populations from primary tumours. To date, no clear robust markers have been characterised that could be exclusively linked with a clonogenic CSC populations. Some of these results have been reviewed elsewhere [136]. Furthermore, since there is no known human homolog of Sca-1, it becomes obvious that BASCs but also vClara cells need further characterisation in order to find their human counterpart. Recently, it has also been demonstrated that both human SCLC and NSCLC contain small populations of undifferentiated cells expressing the cell surface marker prominin-1 (CD133) [137]. Cd133 has been found to be expressed in cancer-primitive cells as well as normal cells from neural, endothelial, epithelial and haematopoietic lineages [138]. Lung cancer CD133 positive cells are able to grow indefinitely as tumour spheres in particular culture conditions and they can generate tumour xenografts in immunocompromised mice, phenotypically identical to the original tumour, while CD133 negative cells do not [137]. Lung cancer contains a rare population of CD133 positive cancer stem-like cells that are able to self-renew and generate an unlimited progeny of nontumorigenic cells [137]. Chemoresistance was observed in the tumour spheres and was associated with increased expression of $A B C$ transporter and embryonal stem cell markers Oct4 and NANOG. Interestingly, after naphthalene treatment in normal mice, a rare population of CD133 positive cells increased. Therefore, it would be very tempting to suggest that those expanding CD133 positive cells are BASCs. Follow-up studies are needed to substantiate this and to translate some the other findings from the mouse models into a better characterisation of human lung CSC.

The bronchial stem cell population could be an ideal candidate for lung cancer progenitors. As these lung stem cells are already endowed with the capacity for self-renewal, they are excellent candidates for the accumulation of deleterious mutations. In fact, accumulating evidence already exist for BASCs that this is indeed the case.

Cells expressing both SP-C and CC10 were first described in the precursor lesions of murine lung tumours initiated by oncogenic Kras [33]. Expression of the oncogenic protein KRAS in these double positive cells induces their proliferation in vivo [33]. Moreover, induction of tumorigenesis in naphthalenetreated $L S L-$ Kras $^{G 12 D}$ mice induced an increase in the number and size of tumours [129]. Furthermore, $\mathrm{Kras}^{\mathrm{G}}{ }^{2 D}$ expression causes BASCs in vitro expansion and generates hyperproliferation at the BADJ in vivo [129]. Similarly, BASCs from p38 $\alpha$ $\mathrm{MAPK}^{-/}$mice were also highly sensitised to $\mathrm{Kras}^{G 12 D}$-induced lung tumorigenesis, leading to an immature and hyperproliferative lung epithelium, thus permitting earlier induction and faster progression to adenocarcinoma [139]. Abrogations of major signalling pathways were shown to be important for the proliferation and maintenance of BASCs. Conditional deletion of PTEN or PI3K in mice result in increased numbers of BASCs and increased propensity to lung tumour development [63, 140]. In $\mathrm{p} 27^{-/-}$mice, BASCs expand first at the BADJ and progress from hyperplasia to adenocarcinomas through dysplasia and adenomas [141]. In contrast, deletion of Bmi1 inhibits tumorigenesis through inhibition of BASC expansion [142]. Taken together, these studies show that BASCs may play a role in the initiation of tumorigenesis but there is still no direct proof of being the initial target cell per se. Indeed CSC may arise from bronchial stem cells but we cannot exclude the fact that they develop from transit-amplifying cells, such as PNECS and Clara cells with each having acquired the ability to self renew as a result of oncogenic mutations. In addition to the acquisition of genetic and epigenetic mutations, interactions between tumour cells and their microenvironment (also called niches, which are composed by the stroma, inflammatory cells and recruited vasculature), has a profound influence on the tumorigenic process. More and more evidence shows that tumour growth can be sustained not only by rare CSC populations but also through dominant (sub) clones or a mixture of both [117]. Although the importance of characterising CSC of lung cancer is of obvious importance, it would be too optimistic as to say that targeting of CSC would cure lung cancer. Most likely a combined targeting of all the different populations is needed to impair tumour growth and prevent long-term recurrence.

\section{PERSPECTIVES AND NEW DIRECTIONS}

The use of mouse models is helping us to understand lung cancer biology by uncovering the critical molecular pathways that govern each stage of tumour formation and progression. It will be important to adjust mouse models for each different human lung cancer type. Progress on genome-wide expression profiling and genomic hybridisation will be helpful in crossspecies analysis of similarities in cancer signalling pathways that govern both mouse and human lung tumorigenesis. These studies will be very useful for the design of inhibitors, which can impair lung tumour growth and can be tested in preclinical mouse models. New, better adapted mouse models with complete human genes could lead to the development of humanised mice that recapitulate human lung cancer at en even higher degree [32]. Rapid advances of lung cancer genome analysis will reveal many additional novel mutations that could be complemented into mouse models for lung cancer.

Metastatic mouse models for both NSCLC and SCLC are now well-established and it will be a challenge to use these models to unravel the mechanism by which lung cancer is often refractory to chemo- and/or radiotherapy. Defined early stages of lung cancer development in combination with noninvasive imaging technologies in these mouse models will be very 
helpful for testing chemoprevention protocols. Another very interesting aspect of the conditional lung tumour models is that they can yield promising biomarkers for lung cancer. Advanced mass spectromy-based proteomics will allow scrutinising analysis of the mouse serum proteome, under both normal and cancerous conditions. There is a clear need for clinically relevant biomarkers of early lung cancer and both somatic mouse models for NSCLC and SCLC show distinct stages in lung tumour development. Combining gene expression profiling with proteomics of these early murine lung tumours will hopefully lead to the discovery of new, relevant biomarkers that can be translated into diagnostic use. A major challenge will not be the discovery but the evaluation of candidate biomarkers through proper validation on patient samples.

The extra-ordinary power of mouse genetics will continue to help us identify lung tumour precursor cells by selective targeting of lung epithelial cell compartments. Candidate precursor cells could then be tagged with reporter genes so one can follow whether they behave like cancer stem cells during tumour growth.

Much progress has been achieved on mouse models for human lung cancer (table 1, fig. 3), but further characterisation is still needed for most NSCLC and SCLC models. It is also important to note that the development of mouse models for SCC clearly lacks behind. A better knowledge of the cell of origin of lung SCC, together with identifying the most suited genetic lesions that cause this lung cancer type, might facilitate proper design of a mouse model.

Finally, we have seen that mouse models for lung cancer have already helped us to further our insight in basic lung cancer biology and test lung cancer therapies. These models still hold many promises within these fields and should be expanded by finding new markers for lung cancer diagnosis. Results will undoubtedly fulfil some of these promises and be importance in the fight against human lung cancer.

\section{SUPPORT STATEMENT}

S. de Seranno was supported by a Postdoctorate grant (Instiut National du Cancer, Paris, France) and R. Meuwissen was supported by a Jeune Chercheur fellowship (INSERM, Paris).

\section{STATEMENT OF INTEREST}

None declared.

\section{REFERENCES}

1 Wakamatsu N, Devereux TR, Hong HH, et al. Overview of the molecular carcinogenesis of mouse lung tumor models of human lung cancer. Toxicol Pathol 2007; 35: 75-80.

2 Shimkin MB, Stoner GD. Lung tumors in mice: application to carcinogenesis bioassay. Adv Cancer Res 1975; 21: 1-58.

3 Pfeifer GP, Denissenko MF, Olivier M, et al. Tobacco smoke carcinogens, DNA damage and p53 mutations in smokingassociated cancers. Oncogene 2002; 21: 7435-7451.

4 Witschi H. A/J mouse as a model for lung tumorigenesis caused by tobacco smoke: strengths and weaknesses. Exp Lung Res 2005; 31: 3-18.

5 Hutt JA, Vuillemenot BR, Barr EB, et al. Life-span inhalation exposure to mainstream cigarette smoke induces lung cancer in
B6C3F1 mice through genetic and epigenetic pathways. Carcinogenesis 2005; 26: 1999-2009.

6 Sato M, Shames DS, Gazdar AF, et al. A translational view of the molecular pathogenesis of lung cancer. J Thorac Oncol 2007; 2: 327-343.

7 Malkinson AM. Primary lung tumors in mice as an aid for understanding, preventing, and treating human adenocarcinoma of the lung. Lung Cancer 2001; 32: 265-279.

8 You M, Wang Y, Nash B, et al. K-ras mutations in benzotrichlorideinduced lung tumors of A/J mice. Carcinogenesis 1993; 14: 1247-1249.

9 Chen B, Johanson L, Wiest JS, et al. The second intron of the K-ras gene contains regulatory elements associated with mouse lung tumor susceptibility. Proc Natl Acad Sci USA 1994; 91: 1589-1593.

10 DeMayo FJ, Finegold MJ, Hansen TN, et al. Expression of SV40 T antigen under control of rabbit uteroglobin promoter in transgenic mice. Am J Physiol 1991; 261: L70-L76.

11 Sandmoller A, Halter R, Gomez-La-Hoz E, et al. The uteroglobin promoter targets expression of the SV40 T antigen to a variety of secretory epithelial cells in transgenic mice. Oncogene 1994; 9: 2805-2815.

12 Wikenheiser KA, Clark JC, Linnoila RI, et al. Simian virus 40 large $\mathrm{T}$ antigen directed by transcriptional elements of the human surfactant protein $C$ gene produces pulmonary adenocarcinomas in transgenic mice. Cancer Res 1992; 52: 5342-5352.

13 Wikenheiser KA, Whitsett JA. Tumor progression and cellular differentiation of pulmonary adenocarcinomas in SV40 large T antigen transgenic mice. Am J Respir Cell Mol Biol 1997; 16 713-723.

14 Geick A, Redecker P, Ehrhardt A, et al. Uteroglobin promotertargeted c-MYC expression in transgenic mice cause hyperplasia of Clara cells and malignant transformation of T-lymphoblasts and tubular epithelial cells. Transgenic Res 2001; 10: 501-511.

15 Sekido Y, Fong KM, Minna JD. Molecular genetics of lung cancer. Annu Rev Med 2003; 54: 73-87.

16 Jacks T, Fazeli A, Schmitt EM, et al. Effects of an Rb mutation in the mouse. Nature 1992; 359: 295-300.

17 Meuwissen R, Berns A. Mouse models for human lung cancer. Genes Dev 2005; 19: 643-664.

18 Olive KP, Tuveson DA, Ruhe ZC, et al. Mutant p53 gain of function in two mouse models of Li-Fraumeni syndrome. Cell 2004; 119: 847-860.

19 Lang GA, Iwakuma T, Suh YA, et al. Gain of function of a p53 hot spot mutation in a mouse model of Li-Fraumeni syndrome. Cell 2004; 119: 861-872.

20 Smith AJ, Xian J, Richardson M, et al. Cre-loxP chromosome engineering of a targeted deletion in the mouse corresponding to the 3p21.3 region of homozygous loss in human tumours. Oncogene 2002; 21: 4521-4529.

21 Tommasi S, Dammann R, Zhang Z, et al. Tumor susceptibility of Rassf1a knockout mice. Cancer Res 2005; 65: 92-98.

22 Zanesi N, Mancini R, Sevignani C, et al. Lung cancer susceptibility in Fhit-deficient mice is increased by Vhl haploinsufficiency. Cancer Res 2005; 65: 6576-6582.

23 Johnson L, Mercer K, Greenbaum D, et al. Somatic activation of the K-ras oncogene causes early onset lung cancer in mice. Nature 2001; 410: 1111-1116.

24 Jonkers J, Berns A. Conditional mouse models of sporadic cancer. Nat Rev Cancer 2002; 2: 251-265.

25 Lewandoski M. Conditional control of gene expression in the mouse. Nat Rev Genet 2001; 2: 743-755.

26 Gossen M, Bujard H. Tight control of gene expression in mammalian cells by tetracycline-responsive promoters. Proc Natl Acad Sci USA 1992; 89: 5547-5551.

27 Perl AK, Tichelaar JW, Whitsett JA. Conditional gene expression in the respiratory epithelium of the mouse. Transgenic Res 2002; 11: 21-29. 
28 Tichelaar JW, Lu W, Whitsett JA. Conditional expression of fibroblast growth factor-7 in the developing and mature lung. J Biol Chem 2000; 275: 11858-11864.

29 Fisher GH, Wellen SL, Klimstra D, et al. Induction and apoptotic regression of lung adenocarcinomas by regulation of a K-Ras transgene in the presence and absence of tumor suppressor genes. Genes Dev 2001; 15: 3249-3262.

$30 \mathrm{Gu} \mathrm{H}$, Zou YR, Rajewsky K. Independent control of immunoglobulin switch recombination at individual switch regions evidenced through Cre-loxP-mediated gene targeting. Cell 1993; 73: 1155-1164.

31 Meuwissen R, Linn SC, van der Vaulk M, et al. Mouse model for lung tumorigenesis through Cre/lox controlled sporadic activation of the K-Ras oncogene. Oncogene 2001; 20: 6551-6558.

32 Frese KK, Tuveson DA. Maximizing mouse cancer models. Nat Rev Cancer 2007; 7: 654-658.

33 Jackson EL, Willis N, Mercer K, et al. Analysis of lung tumor initiation and progression using conditional expression of oncogenic K-ras. Genes Dev 2001; 15: 3243-3248.

34 Guerra C, Mijimolle N, Dhawahir A, et al. Tumor induction by an endogenous K-ras oncogene is highly dependent on cellular context. Cancer Cell 2003; 4: 111-120.

35 Sweet-Cordero A, Mukherjee S, Subramanian A, et al. An oncogenic KRAS2 expression signature identified by crossspecies gene-expression analysis. Nat Genet 2005; 37: 48-55.

36 Stearman RS, Dwyer-Nield L, Zerbe L, et al. Analysis of orthologous gene expression between human pulmonary adenocarcinoma and a carcinogen-induced murine model. Am J Pathol 2005; 167: 1763-1775.

37 Ji H, Houghton AM, Mariani TJ, et al. K-ras activation generates an inflammatory response in lung tumors. Oncogene 2006; 25 : 2105-2112.

38 Floyd HS, Farnsworth CL, Kock ND, et al. Conditional expression of the mutant Ki-rasG12C allele results in formation of benign lung adenomas: development of a novel mouse lung tumor model. Carcinogenesis 2005; 26: 2196-2206.

39 You M, Candrian U, Maronpot RR, et al. Activation of the Ki-ras protooncogene in spontaneously occurring and chemically induced lung tumors of the strain A mouse. Proc Natl Acad Sci USA 1989; 86: 3070-3074.

40 Omer CA, Kohl NE. CA1A2X-competitive inhibitors of farnesyltransferase as anti-cancer agents. Trends Pharmacol Sci 1997; 18: 437-444.

41 Hancock JF. Ras proteins: different signals from different locations. Nat Rev Mol Cell Biol 2003; 4: 373-384.

42 To MD, Wong CE, Karnezis AN, et al. Kras regulatory elements and exon $4 \mathrm{~A}$ determine mutation specificity in lung cancer. Nat Genet 2008; 40: 1240-1244.

43 Berns A. Kras and Hras - what is the difference? Nat Genet 2008; 40: 1149-1150.

44 Zhang Z, Wang Y, Vikis HG, et al. Wildtype Kras2 can inhibit lung carcinogenesis in mice. Nat Genet 2001; 29: 25-33.

45 Wang $\mathrm{Y}$, Zhang Z, Lubet RA, et al. A mouse model for tumor progression of lung cancer in ras and p53 transgenic mice. Oncogene 2006; 25: 1277-1280.

46 Ji H, Wang Z, Perera SA, et al. Mutations in BRAF and KRAS converge on activation of the mitogen-activated protein kinase pathway in lung cancer mouse models. Cancer Res 2007; 67: 4933-4939.

47 Davies H, Bignell GR, Cox C, et al. Mutations of the BRAF gene in human cancer. Nature 2002; 417: 949-954.

48 Shigematsu H, Gazdar AF. Somatic mutations of epidermal growth factor receptor signaling pathway in lung cancers. Int $J$ Cancer 2006; 118: 257-262

49 Dankort D, Filenova E, Collado M, et al. A new mouse model to explore the initiation, progression, and therapy of BRAFV600Einduced lung tumors. Genes Dev 2007; 21: 379-384.
50 Shaw AT, Meissner A, Dowdle JA, et al. Sprouty-2 regulates oncogenic K-ras in lung development and tumorigenesis. Genes Dev 2007; 21: 694-707.

51 Kissil JL, Walmsley MJ, Hanlon L, et al. Requirement for Rac1 in a K-ras induced lung cancer in the mouse. Cancer Res 2007; 67: 8089-8094.

52 Samuels Y, Velculescu VE. Oncogenic mutations of PIK3CA in human cancers. Cell Cycle 2004; 3: 1221-1224.

53 Angulo B, Suarez-Gauthier A, Lopez-Rios F, et al. Expression signatures in lung cancer reveal a profile for EGFR-mutant tumours and identify selective PIK3CA overexpression by gene amplification. J Pathol 2008; 214: 347-356.

54 Engelman JA, Chen L, Tan X, et al. Effective use of PI3K and MEK inhibitors to treat mutant Kras G12D and PIK3CA H1047R murine lung cancers. Nat Med 2008; 30: 30.

55 Gupta S, Ramjaun AR, Haiko P, et al. Binding of ras to phosphoinositide 3-kinase p110alpha is required for ras-driven tumorigenesis in mice. Cell 2007; 129: 957-968.

56 Jakowlew SB. Transforming growth factor-beta in cancer and metastasis. Cancer Metastasis Rev 2006; 25: 435-457.

57 Sun L. Tumor-suppressive and promoting function of transforming growth factor beta. Front Biosci 2004; 9: 1925-1935.

58 Pandey J, Umphress SM, Kang Y, et al. Modulation of tumor induction and progression of oncogenic K-ras-positive tumors in the presence of TGF-b1 haploinsufficiency. Carcinogenesis 2007; 28: 2589-2596.

59 Lynch TJ, Bell DW, Sordella R, et al. Activating mutations in the epidermal growth factor receptor underlying responsiveness of non-small-cell lung cancer to gefitinib. $N$ Engl J Med 2004; 350: 2129-2139.

60 Ji H, Li D, Chen L, et al. The impact of human EGFR kinase domain mutations on lung tumorigenesis and in vivo sensitivity to EGFR-targeted therapies. Cancer Cell 2006; 9: 485-495.

61 Politi K, Zakowski MF, Fan PD, et al. Lung adenocarcinomas induced in mice by mutant EGF receptors found in human lung cancers respond to a tyrosine kinase inhibitor or to downregulation of the receptors. Genes Dev 2006; 20: 1496-1510.

62 Ji H, Zhao X, Yuza Y, et al. Epidermal growth factor receptor variant III mutations in lung tumorigenesis and sensitivity to tyrosine kinase inhibitors. Proc Natl Acad Sci USA 2006; 103 7817-7822.

63 Yanagi S, Kishimoto H, Kawahara K, et al. Pten controls lung morphogenesis, bronchioalveolar stem cells, and onset of lung adenocarcinomas in mice. J Clin Invest 2007; 117: 2929-2940.

64 Iwanaga K, Yang Y, Raso MG, et al. Pten inactivation accelerates oncogenic K-ras-initiated tumorigenesis in a mouse model of lung cancer. Cancer Res 2008; 68: 1119-1127.

65 Sanchez-Cespedes M. A role for LKB1 gene in human cancer beyond the Peutz-Jeghers syndrome. Oncogene 2007; 26: 7825-7832.

66 Giardiello FM, Brensinger JD, Tersmette AC, et al. Very high risk of cancer in familial Peutz-Jeghers syndrome. Gastroenterology 2000; 119: 1447-1453.

67 Hearle N, Schumacher V, Menko FH, et al. Frequency and spectrum of cancers in the Peutz-Jeghers syndrome. Clin Cancer Res 2006; 12: 3209-3215.

68 Sanchez-Cespedes M, Parrella P, Esteller M, et al. Inactivation of LKB1/STK11 is a common event in adenocarcinomas of the lung. Cancer Res 2002; 62: 3659-3662.

69 Matsumoto S, Iwakawa R, Takahashi K, et al. Prevalence and specificity of LKB1 genetic alterations in lung cancers. Oncogene 2007; 26: 5911-5918.

70 Ji H, Ramsey MR, Hayes DN, et al. LKB1 modulates lung cancer differentiation and metastasis. Nature 2007; 448: 807-810.

71 Shah U, Sharpless NE, Hayes DN. LKB1 and lung cancer: more than the usual suspects. Cancer Res 2008; 68: 3562-3565. 
72 Ghaffar H, Sahin F, Sanchez-Cepedes M, et al. LKB1 protein expression in the evolution of glandular neoplasia of the lung. Clin Cancer Res 2003; 9: 2998-3003.

73 Hayashita Y, Osada H, Tatematsu Y, et al. A polycistronic microRNA cluster, miR-17-92, is overexpressed in human lung cancers and enhances cell proliferation. Cancer Res 2005; 65: 9628-9632.

74 Kumar MS, Lu J, Mercer KL, et al. Impaired microRNA processing enhances cellular transformation and tumorigenesis. Nat Genet 2007; 39: 673-677.

75 Johnson SM, Grosshans H, Shingara J, et al. RAS is regulated by the let-7 microRNA family. Cell 2005; 120: 635-647.

76 Esquela-Kerscher A, Trang P, Wiggins JF, et al. The let-7 microRNA reduces tumor growth in mouse models of lung cancer. Cell Cycle 2008; 7: 759-764.

77 Kumar MS, Erkeland SJ, Pester RE, et al. Suppression of nonsmall cell lung tumor development by the let-7 microRNA family. Proc Natl Acad Sci USA 2008; 105: 3903-3908.

78 Meuwissen R, Linn SC, Linnoila RI, et al. Induction of small cell lung cancer by somatic inactivation of both Trp53 and Rb1 in a conditional mouse model. Cancer Cell 2003; 4: 181-189.

79 Brambilla E, Lantuejoul S, Sturm N. Divergent differentiation in neuroendocrine lung tumors. Semin Diagn Pathol 2000; 17: 138-148.

80 Wistuba II, Gazdar AF. Characteristic genetic alterations in lung cancer. Methods Mol Med 2003; 74: 3-28.

81 Ho VM, Schaffer BE, Karnezis AN, et al. The retinoblastoma gene $\mathrm{Rb}$ and its family member $\mathrm{p} 130$ suppress lung adenocarcinoma induced by oncogenic K-Ras. Oncogene 2009; 28: 1393-1399.

82 Linnoila RI, Zhao B, DeMayo JL, et al. Constitutive achaete-scute homologue-1 promotes airway dysplasia and lung neuroendocrine tumors in transgenic mice. Cancer Res 2000; 60: 4005-4009.

83 Linnoila RI, Piantadosi S, Ruckdeschel JC. Impact of neuroendocrine differentiation in non-small cell lung cancer. The LCSG experience. Chest 1994; 106: Suppl. 6, 367S-371S.

84 Pei XH, Bai F, Smith MD, et al. p18Ink4c collaborates with Men1 to constrain lung stem cell expansion and suppress non-smallcell lung cancers. Cancer Res 2007; 67: 3162-3170.

85 Wistuba II, Mao L, Gazdar AF. Smoking molecular damage in bronchial epithelium. Oncogene 2002; 21: 7298-7306.

86 Jetten AM, Nervi C, Vollberg TM. Control of squamous differentiation in tracheobronchial and epidermal epithelial cells: role of retinoids. J Natl Cancer Inst Monogr 1992; 93-100.

87 Nettesheim P, Hammons AS. Induction of squamous cell carcinoma in the respiratory tract of mice. J Natl Cancer Inst 1971; 47: 697-701.

88 Rehm S, Lijinsky W, Singh G, et al. Mouse bronchiolar cell carcinogenesis. Histologic characterization and expression of Clara cell antigen in lesions induced by N-nitrosobis-(2chloroethyl) ureas. Am J Pathol 1991; 139: 413-422.

89 Wang Y, Zhang Z, Yan Y, et al. A chemically induced model for squamous cell carcinoma of the lung in mice: histopathology and strain susceptibility. Cancer Res 2004; 64: 1647-1654.

90 Dakir EL, Feigenbaum L, Linnoila RI. Constitutive expression of human keratin 14 gene in mouse lung induces premalignant lesions and squamous differentiation. Carcinogenesis 2008; 29: 2377-2384

91 Calbo J, Meuwissen R, van Montfort E, et al. Genotypephenotype relationships in a mouse model for human smallcell lung cancer. Cold Spring Harb Symp Quant Biol 2005; 70: 225-232.

92 Witschi $\mathrm{H}$. The complexities of an apparently simple lung tumor model: The A/J mouse. Exp Toxicol Pathol 2005; 57: Suppl. 1, 171-181.

93 Belinsky SA, Stefanski SA, Anderson MW. The A/J mouse lung as a model for developing new chemointervention strategies. Cancer Res 1993; 53: 410-416.
94 Chung EL. Chemoprevention of lung cancer by isothiocyanates and their conjugates in A/J mouse. Exp Lung Res 2001; 27: 319-330.

95 You M, Bergman G. Preclinical and clinical models of lung cancer chemoprevention. Hematol Oncol Clin North Am 1998; 12 1037-1053.

96 Wang Y, Zhang Z, Kastens E, et al. Mice with alterations in both p53 and Ink4a/Arf display a striking increase in lung tumor multiplicity and progression: differential chemopreventive effect of budesonide in wild-type and mutant A/J mice. Cancer Res 2003; 63: 4389-4395.

$97 \mathrm{Lu} \mathrm{Y,} \mathrm{Yao} \mathrm{R,} \mathrm{Yan} \mathrm{Y,} \mathrm{et} \mathrm{al.} \mathrm{A} \mathrm{gene} \mathrm{expression} \mathrm{signature} \mathrm{that} \mathrm{can}$ predict green tea exposure and chemopreventive efficacy of lung cancer in mice. Cancer Res 2006; 66: 1956-1963.

98 Yan Y, Lu Y, Wang M, et al. Effect of an epidermal growth factor receptor inhibitor in mouse models of lung cancer. Mol Cancer Res 2006; 4: 971-981.

99 Omer CA, Chen Z, Diehl RE, et al. Mouse mammary tumor virus-Ki-rasB transgenic mice develop mammary carcinomas that can be growth-inhibited by a farnesyl:protein transferase inhibitor. Cancer Res 2000; 60: 2680-2688.

100 Mahgoub N, Taylor BR, Gratiot M, et al. In vitro and in vivo effects of a farnesyltransferase inhibitor on Nf1-deficient hematopoietic cells. Blood 1999; 94: 2469-2476.

101 Hadjantonakis AK, Dickinson ME, Fraser SE, et al. Technicolour transgenics: imaging tools for functional genomics in the mouse Nature Rev Genet 2003; 4: 613-625.

102 Contag CH, Jenkins D, Contag PR, et al. Use of reporter genes for optical measurements of neoplastic disease in vivo. Neoplasia 2000; 2: 41-52.

103 Lyons SK, Meuwissen R, Krimpenfort P, et al. The generation of a conditional reporter that enables bioluminescence imaging of Cre/loxP-dependent tumorigenesis in mice. Cancer Res 2003; 63: 7042-7046.

104 Hanahan D, Weinberg RA. The hallmarks of cancer. Cell 2000; 100: 57-70.

105 Carney DN, Gazdar AF, Bunn PA Jr, et al. Demonstration of the stem cell nature of clonogenic tumor cells from lung cancer patients. Stem cells 1982; 1: 149-164.

106 Reya T, Morrison SJ, Clarke MF, et al. Stem cells, cancer, and cancer stem cells. Nature 2001; 414: 105-111.

107 Weissman IL, Anderson DJ, Gage F. Stem and progenitor cells: origins, phenotypes, lineage commitments, and transdifferentiations. Annu Rev Cell Dev Biol 2001; 17: 387-403.

108 Pardal R, Clarke MF, Morrison SJ. Applying the principles of stem-cell biology to cancer. Nat Rev Cancer 2003; 3: 895-902.

109 Schiller JH. Current standards of care in small-cell and nonsmall-cell lung cancer. Oncology 2001; 61: Suppl. 1, 3-13.

110 Lapidot T, Sirard C, Vormoor J, et al. A cell initiating human acute myeloid leukaemia after transplantation into SCID mice. Nature 1994; 367: 645-648.

111 Bonnet D, Dick JE. Human acute myeloid leukemia is organized as a hierarchy that originates from a primitive hematopoietic cell. Nat Med 1997; 3: 730-737.

112 Al-Hajj M, Wicha MS, Benito-Hernandez A, et al. Prospective identification of tumorigenic breast cancer cells. Proc Natl Acad Sci USA 2003; 100: 3983-3988.

113 Singh SK, Clarke ID, Terasaki M, et al. Identification of a cancer stem cell in human brain tumors. Cancer Res 2003; 63: 5821-5828.

114 Shipitsin M, Polyak K. The cancer stem cell hypothesis: in search of definitions, markers, and relevance. Lab Invest 2008; 88: 459-463.

115 Al-Hajj M, Clarke MF. Self-renewal and solid tumor stem cells. Oncogene 2004; 23: 7274-7282.

116 Visvader JE, Lindeman GJ. Cancer stem cells in solid tumours: accumulating evidence and unresolved questions. Nat Rev Cancer 2008; 8: 755-768. 
117 Adams JM, Strasser A. Is tumor growth sustained by rare cancer stem cells or dominant clones? Cancer Res 2008; 68: 4018-4021.

118 Quintana E, Shackleton M, Sabel MS, et al. Efficient tumour formation by single human melanoma cells. Nature 2008; 456: 593-598.

119 Stripp BR, Reynolds SD. Maintenance and repair of the bronchiolar epithelium. Proc Am Thorac Soc 2008; 5: 328-333.

120 Stripp BR. Hierarchical organization of lung progenitor cells: is there an adult lung tissue stem cell? Proc Am Thorac Soc 2008; 5: 695-698.

121 Evans MJ, Johnson LV, Stephens RJ, et al. Cell renewal in the lungs of rats exposed to low levels of ozone. Exp Mol Pathol 1976; 24: 70-83.

122 Reynolds SD, Giangreco A, Power JH, et al. Neuroepithelial bodies of pulmonary airways serve as a reservoir of progenitor cells capable of epithelial regeneration. Am J Pathol 2000; 156 269-278.

123 Giangreco A, Reynolds SD, Stripp BR. Terminal bronchioles harbor a unique airway stem cell population that localizes to the bronchoalveolar duct junction. Am J Pathol 2002; 161: 173-182.

124 Hong KU, Reynolds SD, Giangreco A, et al. Clara cell secretory protein-expressing cells of the airway neuroepithelial body microenvironment include a label-retaining subset and are critical for epithelial renewal after progenitor cell depletion. Am J Respir Cell Mol Biol 2001; 24: 671-681.

125 Hong KU, Reynolds SD, Watkins S, et al. Basal cells are a multipotent progenitor capable of renewing the bronchial epithelium. Am J Pathol 2004; 164: 577-588.

126 Giangreco A, Shen H, Reynolds SD, et al. Molecular phenotype of airway side population cells. Am J Physiol Lung Cell Mol Physiol 2004; 286: L624-L630.

127 Reynolds SD, Hong KU, Giangreco A, et al. Conditional clara cell ablation reveals a self-renewing progenitor function of pulmonary neuroendocrine cells. Am J Physiol Lung Cell Mol Physiol 2000; 278: L1256-L1263.

128 Engelhardt JF. Stem cell niches in the mouse airway. Am J Respir Cell Mol Biol 2001; 24: 649-652.

129 Kim CF, Jackson EL, Woolfenden AE, et al. Identification of bronchioalveolar stem cells in normal lung and lung cancer. Cell 2005; 121: 823-835.

130 Khoor A, Stahlman MT, Gray ME, et al. Temporal-spatial distribution of SP-B and SP-C proteins and mRNAs in developing respiratory epithelium of human lung. J Histochem Cytochem 1994; 42: 1187-1199.

131 Kim CF. Paving the road for lung stem cell biology: bronchioalveolar stem cells and other putative distal lung stem cells. Am J Physiol Lung Cell Mol Physiol 2007; 293: L1092-L1098.

132 Ivanova NB, Dimos JT, Schaniel C, et al. A stem cell molecular signature. Science 2002; 298: 601-604.

133 McQualter JL, Brouard N, Williams B, et al. Endogenous fibroblastic progenitor cells in the adult mouse lung are highly enriched in the Sca-1 positive cell fraction. Stem cells 2008; 11: 11.

134 Teisanu RM, Lagasse E, Whitesides JF, et al. Prospective isolation of bronchiolar stem cells based upon immunophenotypic and autofluorescence characteristics. Stem cells 2008; 4: 4.
135 Ling TY, Kuo MD, Li CL, et al. Identification of pulmonary Oct-4+ stem/progenitor cells and demonstration of their susceptibility to SARS coronavirus (SARS-CoV) infection in vitro. Proc Natl Acad Sci USA 2006; 103: 9530-9535.

136 Peacock CD, Watkins DN. Cancer stem cells and the ontogeny of lung cancer. J Clin Oncol 2008; 26: 2883-2889.

137 Eramo A, Lotti F, Sette G, et al. Identification and expansion of the tumorigenic lung cancer stem cell population. Cell Death Differ 2008; 15: 504-514.

138 Mizrak D, Brittan M, Alison M. CD133: molecule of the moment J Pathol 2008; 214: 3-9.

139 Ventura JJ, Tenbaum S, Perdiguero E, et al. p38alpha MAP kinase is essential in lung stem and progenitor cell proliferation and differentiation. Nat Genet 2007; 39: 750-758.

140 Yang Y, Iwanaga K, Raso MG, et al. Phosphatidylinositol 3kinase mediates bronchioalveolar stem cell expansion in mouse models of oncogenic K-ras-induced lung cancer. PLOS ONE 2008; 3: e2220.

141 Besson A, Hwang HC, Cicero S, et al. Discovery of an oncogenic activity in p27Kip1 that causes stem cell expansion and a multiple tumor phenotype. Genes Dev 2007; 21: 1731-1746.

142 Dovey JS, Zacharek SJ, Kim CF, et al. Bmi1 is critical for lung tumorigenesis and bronchioalveolar stem cell expansion. Proc Natl Acad Sci USA 2008; 105: 11857-11862.

143 Carraresi L, Tripodi SA, Mulder LC, et al. Thymic hyperplasia and lung carcinomas in a line of mice transgenic for keratin 5driven HPV16 E6/E7 oncogenes. Oncogene 2001; 20: 8148-8153.

144 Bottinger EP, Jakubczak JL, Haines DC, et al. Transgenic mice overexpressing a dominant-negative mutant type II transforming growth factor beta receptor show enhanced tumorigenesis in the mammary gland and lung in response to the carcinogen 7,12dimethylbenz-[a]-anthracene. Cancer Res 1997; 57: 5564-5570.

145 Berard J, Gaboury L, Landers M, et al. Hyperplasia and tumours in lung, breast and other tissues in mice carrying a RAR beta 4 like transgene. EMBO J 1994; 13: 5570-5580.

146 Linnoila RI, Sahu A, Miki M, et al. Morphometric analysis of CC10-hASH1 transgenic mouse lung: a model for bronchiolization of alveoli and neuroendocrine carcinoma. Exp Lung Res 2000; 26: 595-615.

147 Ehrhardt A, Bartels T, Geick A, et al. Development of pulmonary bronchiolo-alveolar adenocarcinomas in transgenic mice overexpressing murine c-myc and epidermal growth factor in alveolar type II pneumocytes. Br J Cancer 2001; 84: 813-818.

148 Kerkhoff E, Fedorov LM, Siefken R, et al. Lung-targeted expression of the c-Raf-1 kinase in transgenic mice exposes a novel oncogenic character of the wild-type protein. Cell Growth Differ 2000; 11: 185-190.

149 Berard J, Laboune F, Mukuna M, et al. Lung tumors in mice expressing an antisense RARbeta2 transgene. FASEB J 1996; 10: 1091-1097.

150 Sunday ME, Haley KJ, Sikorski K, et al. Calcitonin driven v-Haras induces multilineage pulmonary epithelial hyperplasias and neoplasms. Oncogene 1999; 18: 4336-4347.

151 Jackson EL, Olive KP, Tuveson DA, et al. The differential effects of mutant p53 alleles on advanced murine lung cancer. Cancer Res 2005; 65: 10280-10288. 